\title{
ROADMAP TO NET ZERO: DELIVERING SCIENCE- BASED TARGETS IN THE APPAREL SECTOR
}

\section{EXECUTIVE SUMMARY}

\subsection{Highlights}

The apparel industry has seen a proliferation of companies setting science-based targets (SBTs) on climate change. Currently, over 100 apparel and footwear companies have approved SBTs or commitments to set them-a significant increase from a dozen just three years ago. ${ }^{1}$

- Given this momentum, it is imperative to identify how companies and the sector will deliver on these ambitious targets. That is the central objective of this working paper.

Using data from Higg, Sustainable Apparel Coalition, and Textile Exchange, we estimate apparel sector emissions at 1.025 gigatonnes $(\mathrm{Gt})$ of carbon dioxide equivalent $\left(\mathrm{CO}_{2} \mathrm{e}\right)$ in 2019 , or roughly 2 percent of annual global greenhouse gas (GHG) emissions. ${ }^{2}$ Unchecked, emissions will grow to $1.588 \mathrm{Gt}$ by 2030, well off pace to deliver the 45 percent absolute reduction needed to limit warming to $1.5^{\circ} \mathrm{C}$.

- This research identified six interventions that deliver over 60 percent of the necessary reductions to align with a $1.5^{\circ} \mathrm{C}$ scenario: maximizing material efficiency, scaling more sustainable materials and practices, accelerating the development of innovative materials, maximizing energy efficiency, eliminating coal in manufacturing, and shifting to 100 percent renewable electricity. The sector must find solutions to deliver the balance.

The paper also discusses the potential benefits of circular business models and practices, though data on GHG reductions from circularity needs improvement.

\section{CONTENTS}

1. Executive Summary .................................

2. Introduction....................................... 3

3. The State of GHG Data in the Apparel Sector ........ 4

4. Methodology....................................

5. Results ........................................... 11

6. Recommendations for Improving Sector

GHG Emissions Data .............................. 13

7 Reducing Emissions in the Apparel Sector .......... 13

8 Spotlight on the Circular Economy.................20

9 Call to Action ..................................... 23

Appendices........................................ 24

Endnotes............................................... 34

References ............................................ 35

Working Papers contain preliminary research, analysis, findings, and recommendations. They are circulated to stimulate timely discussion and critical feedback, and to influence ongoing debate on emerging issues.

Suggested Citation: Sadowski, M., L. Perkins, and E. McGarvey. 2021. "Roadmap to Net-Zero: Delivering Science-Based Targets in the Apparel Sector." Working Paper. Washington, DC: World Resources Institute. Available online at https://doi.org/10.46830/wriwp.20.00004. 


\subsection{Context}

When World Resources Institute (WRI) initiated work on the Apparel and Footwear Sector Science-Based Targets Guidance in late 2017, there were roughly a dozen apparel and footwear companies that had joined the Science Based Targets initiative (SBTi); by September 2021, over 100 such companies had joined. During this time, the roster of companies has diversified to include brands, retailers, and manufacturers of all sizes and geographic locations.

The Guidance provided a blueprint for apparel companies to set SBTs and offered sector-specific context. Now, the goal of the Roadmap is to provide direction for how companies and the sector can focus collective attention on the most impactful interventions for reducing emissions by 45 percent by 2030 and to net zero by 2050 .

\subsection{About This Report}

The Roadmap was developed by WRI and the Apparel Impact Institute (Aii), with generous support from the Laudes Foundation. Using data from the Sustainable Apparel Coalition (SAC), Higg, and Textile Exchange, we developed an estimate of apparel sector emissions and projected these emissions to 2030 under a business-asusual growth scenario. The Roadmap also highlights key assumptions and limitations in the data sources and offers recommendations for improving the data over time.
The target audience for the Roadmap is apparel companies and the organizations that must be part of the effort to reduce sector emissions. The vast majority of sector emissions lie in the supply chains of brands (tiers 1 through 4). See Figure 1 for an illustration of the value chain and Figure 3 for data on the emissions across Scopes for a selection of apparel and footwear companies with approved SBTs.

\subsection{Research Approach and Baseline Findings}

The objectives of the Roadmap are as follows:

1. Map the major sources of GHG emissions across the apparel value chain.

2. Identify the most impactful actions companies can take to reduce emissions.

3. Highlight the challenges to taking these actions and potential solutions.

4. Identify the organizations and initiatives working to reduce emissions in the sector.

To meet these objectives, we reviewed various reports and studies, including several sector GHG estimates, and interviewed experts from across the industry. We estimate apparel sector emissions to be $1.025 \mathrm{Gt} \mathrm{CO}_{2} \mathrm{e}$ in 2019. Under a business-as-usual growth scenario, ${ }^{3}$ sector emissions will grow to $1.588 \mathrm{Gt}$ by $2030-$ well off

Figure ES-1 | Projected GHG Emissions for the Apparel Sector, 2019-2030

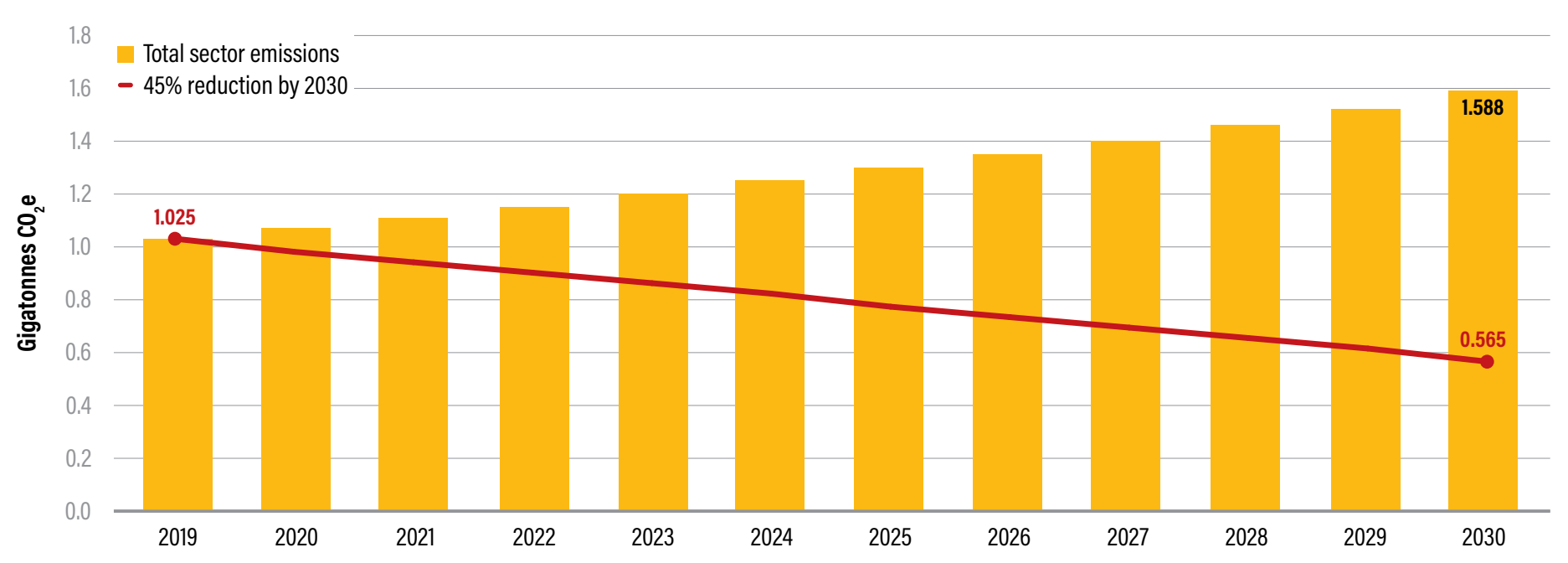

Source: WRI authors. 
pace to deliver 45 percent absolute reduction (see Figure ES-1). Section 3 of this report describes key limitations and assumptions.

\subsection{Key Interventions for Reducing Emissions}

This report identifies six interventions for the sector to reduce emissions:

Maximizing material efficiency. Through design, material selection, and methods of manufacturing, reduce the amount of fiber and materials that go to waste in each stage of production.

\section{Scaling sustainable materials and practices.} Increase the use of more sustainable materials (such as recycled polyester) and practices (for instance, conservation tillage for cotton).

\section{Accelerating the development of innovative} materials. Ramp up investment in next generation materials, including textile recycling, bio-based materials, and plant-based leather.

Maximizing energy efficiency. Expand energy efficiency efforts across manufacturing facilities.

Eliminating coal in manufacturing. Replace coal as a thermal energy source for materials and product manufacturing.

- Shifting to 100 percent renewable electricity. Deploy renewable electricity across the supply chain.

For each intervention, we estimate the potential GHG savings and identify the barriers and solutions to implementation. Combined, these six interventions could deliver over 60 percent of the needed reductions to stay aligned with a 45 percent reduction pathway. For the balance, and to achieve net zero by 2050, the industry will need to develop new materials, methods of manufacturing, and business models. The industry will also need to address what WRI has called the "elephant in the boardroom:" the unchecked consumption of apparel (Putt del Pino et al. 2017).

\subsection{Limitations of the Data Used in the Roadmap}

As described in Section 3, there are limitations in the data used in this report to estimate sector emissions, and we made various assumptions informed by in-depth research.
These limitations and assumptions do not change the findings about the relative distribution of emissions across tiers nor the interventions needed to reduce emissions. In being transparent about our data sources and assumptions, our intent is that the analysis can be improved upon over time.

\section{2 |NTRODUCTION}

\subsection{Overview}

In June 2019, World Resources Institute (WRI) published Apparel and Footwear Sector Science Based Targets Guidance (Sadowski et al. 2019), the objectives of which were to bring clarity and consistency to climate change targets, in turn resulting in more apparel and footwear companies setting science-based targets (SBTs). When WRI initiated work on the Guidance in late 2017, roughly a dozen apparel and footwear companies had joined the Science Based Targets initiative (SBTi); by September 2021, over 100 such companies had joined. ${ }^{4}$

In developing the Guidance, WRI spoke with a variety of industry stakeholders, including brands, retailers, manufacturers, non-governmental organizations (NGOs), consultants, and others. From these conversations and research, we observed that while the Guidance has helped build momentum around SBTs, there was a need to identify how companies could deliver on ambitious greenhouse gas (GHG) emissions reduction targets. There is also a need for the sector to align on where GHG emissions occur across the value chain (Figure 1) and how to reduce these emissions.

This is the ultimate goal for the Roadmap to Net Zero (Roadmap)-it is an input and guide for the collaboration needed to reduce emissions by 45 percent by 2030 and to net zero by 2050 .

With generous support from the Laudes Foundation, WRI partnered with the Apparel Impact Institute (Aii) to develop the Roadmap. This is a natural collaboration given Aii's mission to identify, fund, scale, and measure solutions to accelerate positive impact in the apparel industry. 


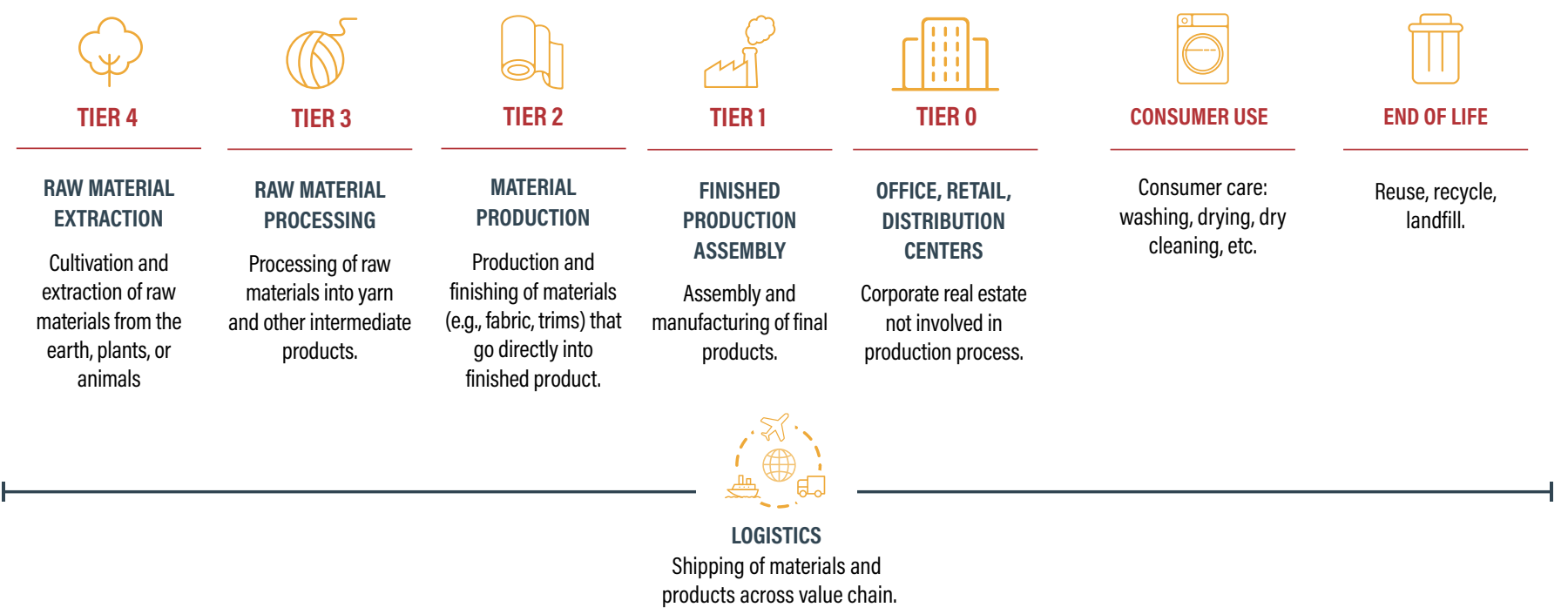

Source: WRI authors.

\subsection{Roadmap Objectives and Approach}

The objectives of the Roadmap are as follows:

1. Map the major sources of GHG emissions across the apparel value chain. ${ }^{5}$

2. Identify the most impactful actions companies can take to reduce emissions.

3. Highlight the challenges to taking these actions and potential solutions.

4. Identify the organizations and initiatives working to reduce emissions in the sector.

To deliver these objectives, we completed a literature review and interviewed experts from across the industry. We partnered with the Sustainable Apparel Coalition (SAC) and Higg to develop an estimate of apparel sector GHG emissions based on the Higg Materials Sustainability Index (MSI) and measure the impact of different interventions. This methodology is detailed in Section 4.

\section{THE STATE OF GHG DATA IN THE APPAREL}

\section{SECTOR}

\subsection{Overview}

Ideally, we would calculate sector GHG emissions by gathering activity data for all entities across the value chain: brands, manufacturers, mills, material processors, cotton farms, logistics providers, and more. For example, for a
B0X 1 | Overview of the Higg Index

Developed by the SAC, the Higg Index is a suite of tools that enables brands, retailers, and manufacturers to measure company and product sustainability performance. The Higg Index has several modules, including the MSI, which allows companies to measure their environmental impact from raw material to finished fabric. MSI data comes from sources such as life cycle assessment (LCA) databases and submissions from companies.

In the future, the Higg Facility Environmental Module (FEM) will be a valuable tool in developing more accurate estimates of apparel sector emissions given the increasing volume of company- and product-specific data collected through it. In the 2019 FEM cycle, over 10,800 FEM modules were shared with value chain partners. For additional context and statistics on the Higg Index, see the SAC report $A$ Decade in Review.

Notes: a. For more information about the Higg Index, see https://apparelcoalition. org/the-higg-index.

b. SAC 2020a.

Source: WRI authors. 
cut and sew facility, calculations would include activity data and emissions factors specific to the electricity and fuel used by the facility. For a cotton farm, calculations would draw from activity data and emissions factors from the energy source used for equipment and inputs such as fertilizer. And so on, across the thousands of entities within the value chain.

However, such primary data ${ }^{6}$ generally either does not exist or is incomplete. Given the large number of entities operating in the value chain, gathering this data will be a significant undertaking that will take years.

As the industry works to improve impact data, estimates of sector GHG footprints-including the estimates in this Roadmap-should be viewed as rough and directional. These estimates are valuable in identifying the relative distribution of emissions across the value chain and allow companies to prioritize action. However, they do not provide a strong foundation for making claims about the percentage contribution of the apparel industry to global GHG emissions.

The estimates included in this publication and previous estimates are based on secondary or average data (Table 1). For example, MSI data was used to calculate the sector- level emissions from cotton farming; that data is based on the average emissions from cotton grown in China, India, Australia, and the United States. For spinning cotton fiber into yarn, MSI data is based on average energy use in textile facilities.

B0X 2 | Illustrating the Challenge of Gathering Primary Data

- H\&M has nearly 1,800 tier 1 factories and more than 300 tier 2 mills.

- adidas has over 500 tier 1 factories and subcontractors and roughly 150 wet processing facilities.

- C\&A has roughly 1,600 tier 1 and 2 facilities.

- There are over 16,000 cotton farmers in the United States alone.

Reducing emissions in the sector will take engagement with thousands of suppliers to measure emissions and identify and implement reductions.

Note: Data drawn from supplier lists produced H\&M (2021a), adidas (2021), and C\&A (2018), respectively, while the cotton farm estimation was supplied by correspondence with Cotton Incorporated (Daystar 2021).

Source: Compiled by WRI authors.

Table 1 | Data Sources for Previous Studies

\begin{tabular}{|c|c|c|c|}
\hline RESEARCH PUBLICATION & SCOPE & KEY DATA SOURCES & RESULTS \\
\hline $\begin{array}{l}\text { Redesigning Fashion's } \\
\text { Future (2017), Ellen MacAr- } \\
\text { thur Foundation } \\
\text { and McKinsey }\end{array}$ & $\begin{array}{l}\text { Categories: Apparel } \\
\text { Geography: Global } \\
\text { Value chain: Raw materials to finished } \\
\text { product }\end{array}$ & $\begin{array}{l}\text { Various: USDA, Lenzing, IHS, } \\
\text { Gherzi, etc. } \\
\text { Emissions factors come from } \\
\text { McKinsey analysis }\end{array}$ & $\begin{array}{l}2 \text { billion tonnes of } \mathrm{CO}_{2} \mathbf{e} \\
2 \% \text { of global carbon budget under } \\
2^{\circ} \mathrm{C} \text { pathway }\end{array}$ \\
\hline $\begin{array}{l}\text { Measuring Fashion: } \\
\text { Environmental Impact of } \\
\text { the Global Apparel and } \\
\text { Footwear Industries Study } \\
\text { (2018), Quantis }\end{array}$ & $\begin{array}{l}\text { Categories: Apparel and footwear } \\
\text { Geography: Global } \\
\text { Value chain: Raw materials to end of life }\end{array}$ & $\begin{array}{l}\text { Apparel fiber volume data from } \\
\text { Fiber Year } 2017 \\
\text { Footwear data from World Footwear } \\
\text { Yearbook } 2012 \\
\text { Quantis World Apparel \& Footwear } \\
\text { Life Cycle Assessment Database } \\
\text { (WALDB) }\end{array}$ & $\begin{array}{l}3.29 \text { billion tonnes of } \mathrm{CO}_{2} \mathbf{e} \\
6.7 \% \text { of global } \mathrm{CO}_{2} \text { e emissions } \\
\text { (Figures cover only apparel) }\end{array}$ \\
\hline $\begin{array}{l}\text { Fashion on Climate: How } \\
\text { the Fashion Industry Can } \\
\text { Urgently Act to Reduce Its } \\
\text { Greenhouse Gas Emissions } \\
\text { (2020), Global Fashion } \\
\text { Agenda and McKinsey }\end{array}$ & $\begin{array}{l}\text { Categories: Apparel and footwear } \\
\text { Geography: Global } \\
\text { Value chain: Raw materials to end of life }\end{array}$ & $\begin{array}{l}\text { Fiber volume data from Fiber Year } \\
2019 \\
\text { Emissions factors from McKinsey } \\
\text { proprietary data and reports }\end{array}$ & $\begin{array}{l}2.1 \text { billion tonnes of } \mathrm{CO}_{2} \mathbf{e} \\
4 \% \text { of global emissions }\end{array}$ \\
\hline
\end{tabular}


Using secondary data to calculate a sector-wide GHG footprint has several limitations:

Available emissions factors may not be representative of actual industry activities or practices. For example, polyester raw material data in the MSI comes from European production ( $\mathrm{GaBi} 2019)$ and thus does not cover polyester manufactured in China, the largest producer of polyester inputs globally (The Fiber Year Consulting 2020). If Chinese production is more carbon-intensive than European, calculations based on the MSI will underestimate polyester raw materials emissions. ${ }^{7}$

Available emissions factors are generally derived from LCAs of specific products or materials or by comparing LCAs of multiple products or materials, under defined system boundaries. The variables and assumptions in these LCAs may not be transferable to products or materials in other contexts. For example, organic cotton data in the MSI is based on average data from four countries, and organic cotton grown elsewhere may have different impacts.

Secondary data does not allow companies or the sector to track performance over time because the emissions factors are not based on actual activities nor are they generally updated on a regular basis. For example, if a company calculates tier 4 wool GHG emissions by multiplying the mass of wool fiber used by the MSI data point, future emissions will only vary by the change in the amount of wool used-the emissions factor will likely not change. Secondary data can help a company and the sector to understand hotspots of emissions, but primary data is needed to track reductions over time.

Ultimately, better primary data is needed to make more robust calculations of sector emissions. Given the size and complexity of the industry, this will take many years. The Higg FEM is helping to scale the collection of primary data from manufacturers and can be extended to other parts of the value chain, such as spinning. Brands can help accelerate this process by working with suppliers to access primary data. In the meantime, the MSI can be updated and expanded to cover more materials and newer data points, including primary data submitted through the MSI Contributor (SAC 2020b). Over time, the suite of Higg modules can be used to gather GHG data from downstream portions of the value chain, as illustrated in Figure 2.

While it will take time to improve the data, the sector knows enough about the hotspots of emissions to act now.

Figure 2 | Higg Coverage across the Value Chain

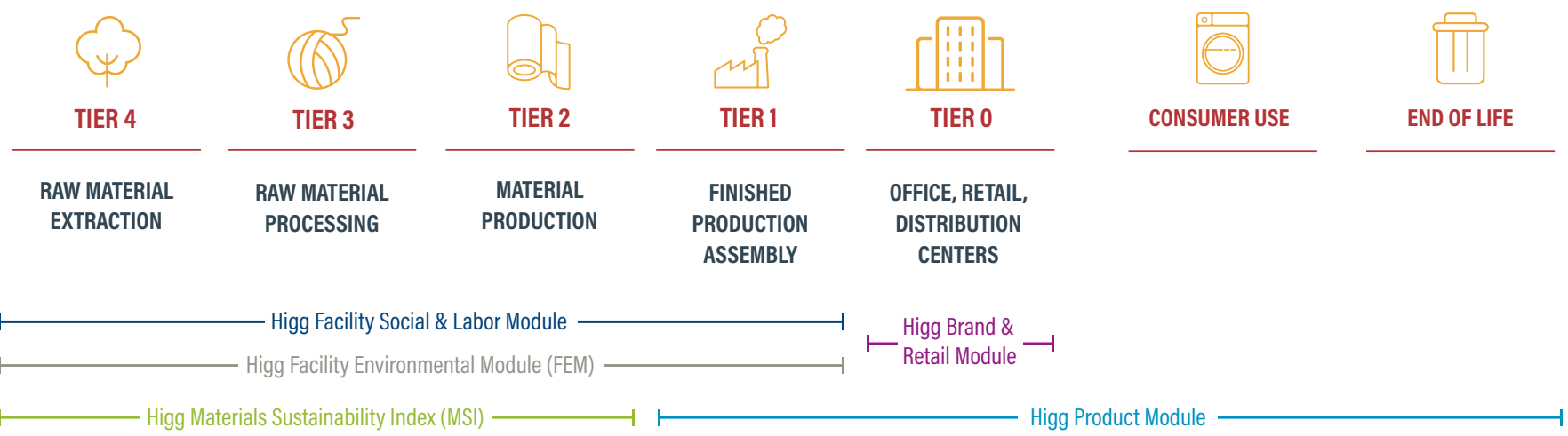




\subsection{Illustration of Emissions for Apparel Companies with Approved SBTs}

To illustrate the distribution of emissions across the sector, Figure 3 shows the breakdown of emissions for a selection of 30 apparel and footwear brands and retailers with approved targets from the SBTi. Scope 3 emissions represent nearly all of the emissions for these companies, and purchased goods and services account for the vast majority of Scope 3 emissions.

\section{METHODOLOGY}

\subsection{Overview}

While analyses like those in Table 1 are useful in identifying hotspots of emissions across the apparel value chain, they do not provide a robust baseline for measuring sector progress over time, given the challenges and limitations described above. Previous sector estimates differ considerably-from 1.2 Gt to 3.29 Gt-due to varying data inputs, assumptions, and methodologies.

In using the MSI to estimate apparel sector emissions, we face the same challenges. However, given broad industry use of the MSI, the potential for expanding and improving MSI data, and the link to the FEM (for primary data in the future), the MSI and the Higg Index are the best available data sets for developing more robust sector GHG footprints, recognizing the limitations acknowledged in Section 3. The analysis for the Roadmap also used fiber weight data from Textile Exchange's Preferred Fiber \& Materials Market Report (PFMMR) (2020a). The Roadmap covers apparel only as data is more readibly available, but future analyses should include footwear as well.

As with previous studies, this analysis is based on various assumptions and imperfect data; the Roadmap documents these in hopes that it will contribute towards improving future analysis. As the MSI and fiber data is updated, the sector will be able to more readily measure and report on progress using consistent and widely accepted data. Improved MSI and FEM data will also help companies more accurately track performance against SBTs.

\subsection{Research Approach}

To develop an estimate of sector emissions, we started with fiber weight data compiled by Textile Exchange in the PFMMR (2020a). This includes global production weights of various fibers and materials used in textiles in 2019. The fiber data covers the total amount of fibers produced-it does not differentiate between use in apparel, home textiles, technical textiles, or other applications. Based on feedback from several stakeholders, including

\section{Figure 3 | Breakdown of Emissions for a Selection of Companies with Approved SBTS}

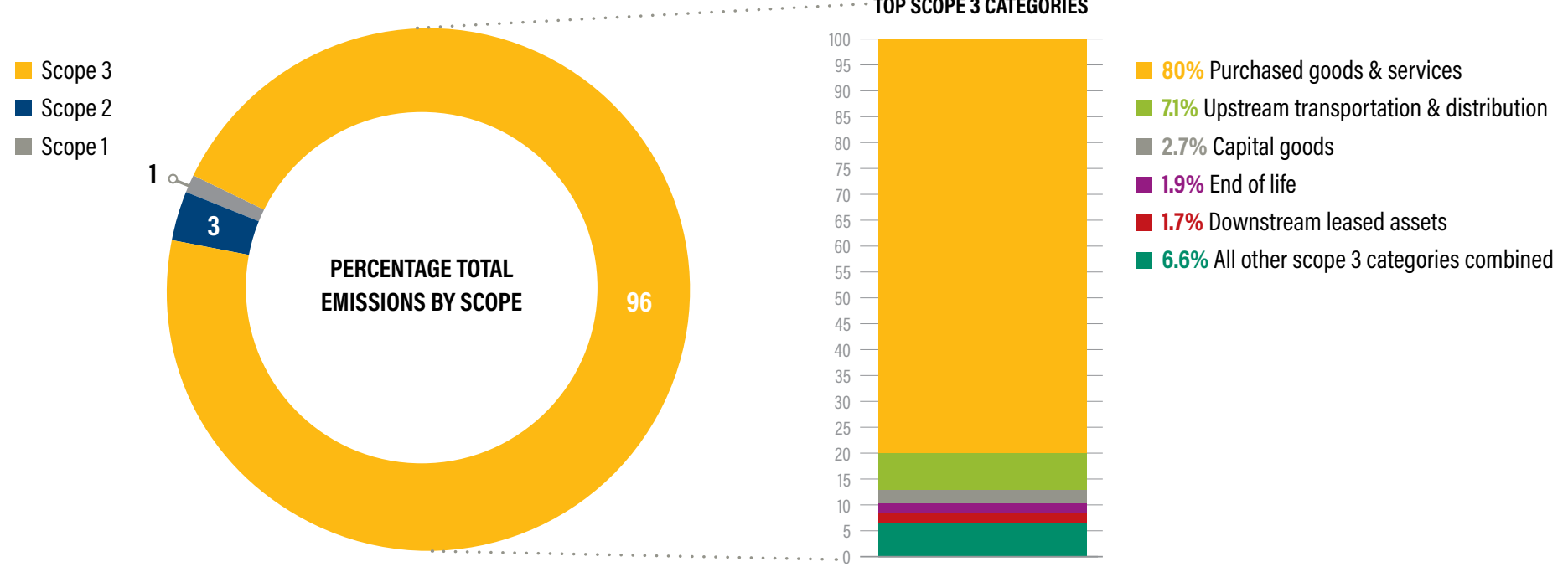

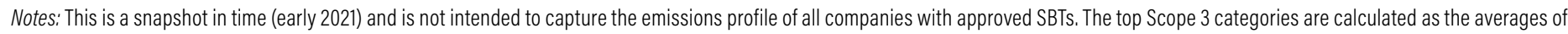
approximately 30 companies with approved science-based targets.

Source: WRI authors. 
Cotton Incorporated and Textile Exchange, this research assumes that approximately 66 percent of all fibers are used in apparel. ${ }^{8}$

For each fiber type, we multiplied total fiber weight by the GHG emissions factor for each process stage in the MSI:

Raw material, such as cotton farming to gin

Yarn formation, or spinning fiber into yarn

Textile formation, such as knitting or weaving yarn into fabric

Preparation, such as scouring

\section{Coloration}

- Additional coloration and finishing, including heat setting

These calculations were based on assumptions specific to each fiber type. For example, based on the literature review and expert feedback, we assumed 67 percent of all polyester yarn was filament and 33 percent was staple. ${ }^{9}$ This specificity is important, as MSI emissions factors differ across fiber types, yarn types, and processes (for example, knit versus woven). More detail on the calculations for each stage is provided below and in the appendices.
B0X 3 | Note on Transparency and the MSI

When the draft Roadmap was released in September 2020, we received several requests to disclose the MSI emissions factors used in our analysis. While we recognize the importance of such transparency, we cannot disclose emissions factors for several reasons. First, the SAC and Higg have licensing agreements with database providers (for instance, Sphera's GaBi) that dictate how data can be used. Second, the MSI contains proprietary data from individual companies that do not want their data shared in more detail than the SAC and Higg currently provide (life cycle impact assessment midpoints).

That said, we have tried to be as detailed as possible in presenting sources for the various processes contributing to these calculations. The SAC has published the detailed methodology for the MSI ${ }^{\mathrm{a}}$ along with other resources, including regular change logs ${ }^{b}$ and frequently asked questions. ${ }^{c}$ When using the free version of the MSI, a user can see data descriptions and sources, as well as evaluations of data quality.

Notes:

a. SAC 2020c.

b. SAC 2021a.

c. SAC 2021b.

Source: WRI authors

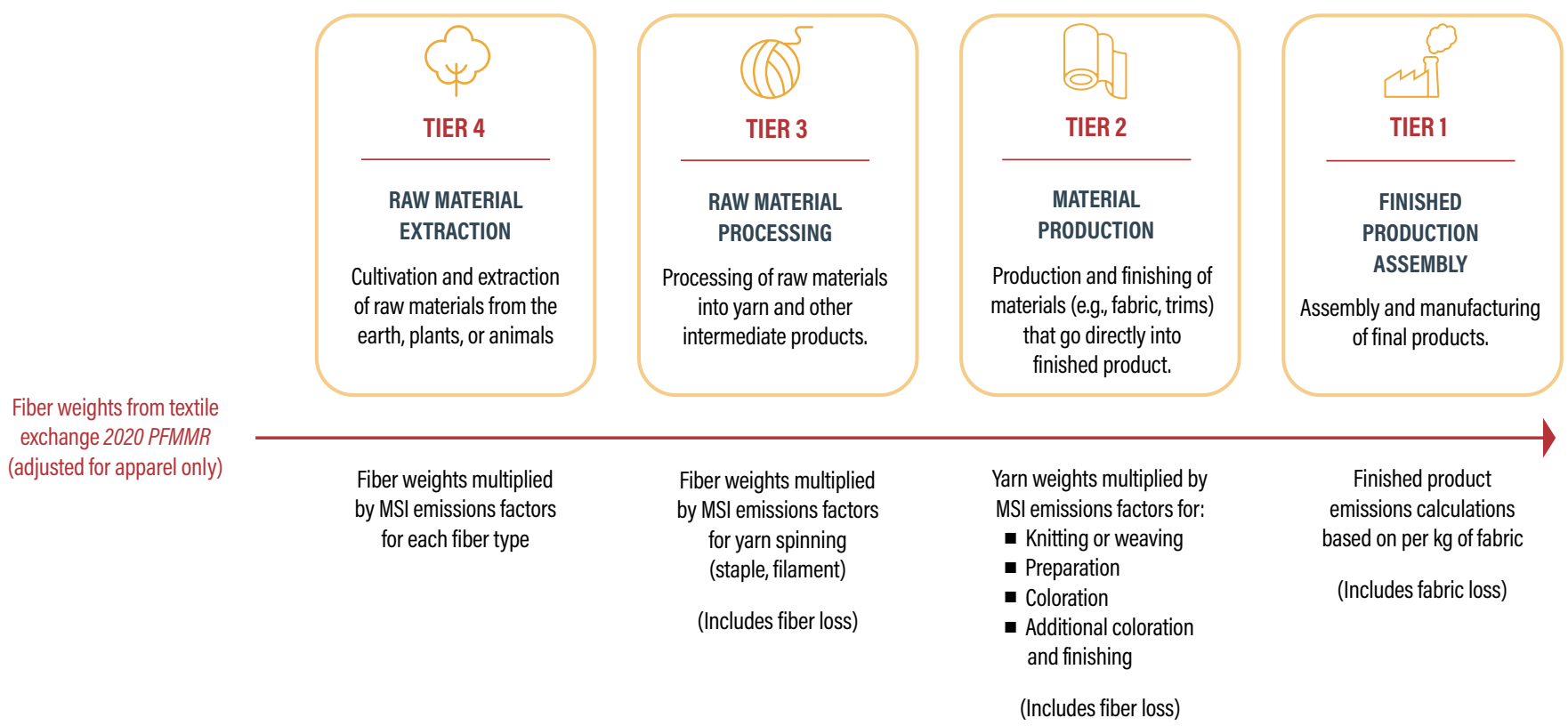

Source: WRI authors. 
Since the MSI does not include data on finished goods production (tier 1), the calculation use a simplified process from Quantis' World Apparel \& Footwear Life Cycle Assessment Database (WALDB) as a proxy (Quantis 2021). Nonetheless, it is important to recognize that energy requirements can vary significantly across apparel product categories. In the future, the FEM can be used to gather primary data for tier 1.

The MSI includes a base-level of emissions for transportation of intermediate materials between production phases; this is included in the analysis. ${ }^{10}$

The research focused on the four tiers of the value chain, as illustrated in Figure 4. Based on the analysis of approved SBTs, these four tiers represent the vast majority of emissions in the sector (over 80 percent). The estimate excludes the following:

\section{Corporate offices and other buildings.}

Emissions from these sources are typically small relative to product- and manufacturingrelated emissions.

Consumer use. While some studies find that emissions from washing and drying can be significant, companies report that calculating use phase emissions is challenging given a lack of actual consumer behavior data. Also, it can be difficult for brands to influence consumer behavior, though brands such as Levi's are making efforts.

End of life. Estimating emissions from landfilling or incinerating apparel is challenging, though based on data in Figure 3, they are low relative to supply chain emissions.

Downstream transportation. Based on our analysis of companies with approved SBTs, downstream transportation (in other words, retailer to consumer) comprises roughly 2 percent of total emissions.

\subsection{Key Assumptions and Limitations}

\subsubsection{Raw Material Extraction (Tier 4)}

Scope: Emissions related to extracting fossil fuels for conversion into synthetic fibers and growing natural fibers such as cotton and wool.

According to the PFMMR, roughly 111 million tonnes (Mt) of fiber were produced for textiles in 2019. For the purposes of this analysis, acetate fiber, jute, and coir were removed from that total, as these fibers are generally not used in apparel. As described in section 4.2, our calculations also assume that 66 percent of all fiber is used for apparel. Taking all of these into consideration, the starting point for fiber used in apparel was 68.7 million tonnes of fiber (see details in Appendix C).

This analysis makes use of the same fiber percentages reported in the PFMMR. Polyester was the most used fiber type in 2019, representing 52 percent of all fiber, with cotton second at 23 percent, followed by man-made cellulosic fibers (MMCF) at 6.4 percent and nylon at 5 percent. This analysis excludes leather, as 2020 was the first year that the PFMMR collected data on it.

For tier 4, we then multiplied the weights of each fiber type by the corresponding emissions factor from the MSI and summed these for a total tier 4 number.

\subsubsection{Raw Material Processing (Tier 3)}

\section{Scope: Spinning fiber into yarn.}

This analysis focused on spinning fibers into yarn and did not include the processing of other intermediate materials, such as metal for zippers and chemicals for dyes, as that data is not readily available. Including these other materials in the future would enable a more complete analysis. 
Table 2 | Assumptions for Yarn Types ${ }^{\mathrm{a}}$

\begin{tabular}{|l|l|}
\hline FIBER & ASSUMPTIONS \\
\hline Polyester & $\begin{array}{l}67 \% \text { filament yarn } \\
33 \% \text { staple fiber ring spun yarn }\end{array}$ \\
\hline Nylon & $\begin{array}{l}\text { 90\% filament yarn } \\
10 \% \text { staple fiber ring spun yarn }\end{array}$ \\
\hline Polypropylene & $60 \%$ filament yarn \\
& $40 \%$ staple fiber ring spun yarn \\
\hline Acrylic & $100 \%$ staple fiber ring spun yarn \\
\hline MMCF (Viscose Rayon, & $100 \%$ staple fiber ring spun yarn ${ }^{d}$ \\
\hline Modal, Lyocell) & \\
\hline Cotton & $75 \%$ staple fiber ring spun yarn \\
& $25 \%$ staple fiber rotor spun yarn \\
\hline
\end{tabular}

Notes:

a. Filament fibers-generally synthetics-have practically unlimited lengths. Staple fibers such as cotton have shorter or finite lengths.

b. This analysis uses Nylon 6 data because it is the majority of nylon used by the apparel industry. Also, in the current LCA datasets, there is not a large difference in the footprint between Nylon 6 and Nylon 6.6, as the differences are far up the LCA background data chain.

c. Data on staple fiber spun yarn is not available, so this was instead modelled as a non-woven textile using filament yarn.

d. According to stakeholder feedback, this breakdown is likely 95 percent staple fiber and 5 percent filament, but the analysis assumes 100 percent staple as the MSI does not have data for filament.

e. Per stakeholder feedback, this breakdown is likely 70 percent ring spun, 25 percent rotor spun, and 5 percent air jet. The MSI does not have data on air jet, so we used 75 percent ring spun and 25 percent rotor spun.

Source: WRI authors.

Informed by stakeholder feedback, we made several assumptions for converting fiber into yarn, detailed in Table 2.

To simplify the analysis, we assumed a yarn density of 200 decitex (dtex) for all fiber types. ${ }^{11}$

Fiber loss rates were drawn from the Higg MSI, which are created from Textile Exchange's Corporate Fiber \& Materials Benchmark 2019 Fiber Conversion Methodology (2019a). These rates differ by fiber type and yarn format. For example, the loss rate for polyester filament yarn is 3 percent, while the loss rate for polyester staple yarn is 9 percent (Appendix D).

\subsubsection{Material Production (Tier 2)}

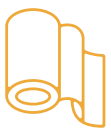

Scope: Textile formation, preparation, coloration, and additional coloration and finishing.

For tier 2, the analysis covers four stages:

Textile formation, such as knitting or weaving yarn into fabric

- Preparation, such as scouring

- Coloration

- Additional coloration and finishing, such as heat setting

Based on stakeholder input, previous research, and our own experience, we assumed 40 percent knit and 60 percent woven for all fiber types for textile formation. While these percentages likely vary by individual fiber type, the approximation helps to simplify analysis. Small differences in this ratio would have a notable impact on emissions, given the considerably higher emissions for weaving as compared to knitting. For instance, for cotton, emissions from weaving are 19 times higher than for knitting.

For preparation, default MSI emissions factors were applied for each fiber type. The sources for these emissions factors can be found in the public version of the MSI (SAC 2020d).

For coloration, the default MSI emissions factors were again applied for each fiber type:

Synthetic fibers: Batch dyeing with disperse or cationic dyes

Cotton and MMCF fibers: Batch dyeing with direct, sulfur, vat, or reactive dyes

Wool: Batch dyeing with acid dyes

Data on actual coloration methods across fabrics used would support a more robust calculation of the sector GHG footprint. Companies wanting to get more granular on GHG emissions from coloration can select specific coloration methods in the MSI. The choice of coloration can have a significant impact on emissions. Solution dyeing, for example, is considerably less carbon-intensive than batch dyeing. ${ }^{12}$ 
Expanding on the calculations from the Roadmap draft, this analysis also includes a stage for heat setting for all fabrics. Heat setting is a thermal treatment that imparts shape retention, elasticity, and other characteristics to fabrics. As with coloration, companies with specific fabric manufacturing data can add other processes, such as screen printing, for a more granular GHG calculation.

As with tier 3, calculations use fiber loss rates from the MSI (via Textile Exchange) for tier 2.

\subsubsection{Finished Goods Manufacturing (Tier 1)}

Scope: Final assembly of products, including cutting and sewing of fabric into garments.

Since the MSI applies only to material production (tiers 2,3 , and 4), we calculated finished goods manufacturing emissions using a standard emission factor per kilogram of finished product. We started with a simplified process from Quantis' WALDB and remodeled it in GaBI. The process includes GHG impacts from electricity consumption (8o percent of the GHG impact), thermal energy, and minor sources such as tap water. Calculations used the electricity mix representing the top apparel manufacturing countries, which is consistent with the MSI. ${ }^{13}$

Calculations assumed an average fabric loss rate of 20 percent for finished goods, though actual loss rates can vary by product type. Scrap fabric is often downcycled by factories-for example, used as stuffing in toys-but it is not possible to calculate the GHG impacts due to a lack of data.

\section{THE RESULTS}

Based on our calculations, total GHG emissions for 2019 for the apparel sector are estimated to be 1.025 billion tonnes of carbon dioxide equivalent $\left(\mathrm{CO}_{2} \mathrm{e}\right)$, or 1.025 Gt. Based on global annual GHG emissions of $49.4 \mathrm{Gt}$, this represents roughly 2 percent of global emissions (WRI 2020).

Given the magnitude of tier 2 emissions (52 percent), the analysis further breaks down emissions for activities within that tier: $203 \mathrm{Mt}$ in textile formation, $108 \mathrm{Mt}$ in preparation, $144 \mathrm{Mt}$ in coloration, and $80 \mathrm{Mt}$ in additional coloration and finishing.
Total Apparel GHG Emissions: 1.025 billion tonnes $\mathrm{CO}_{2} \mathrm{e}$ (1.025 Gt)
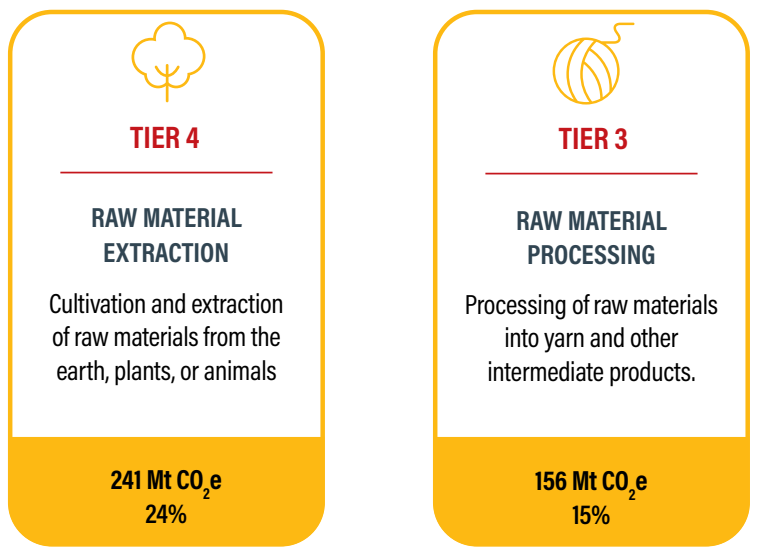

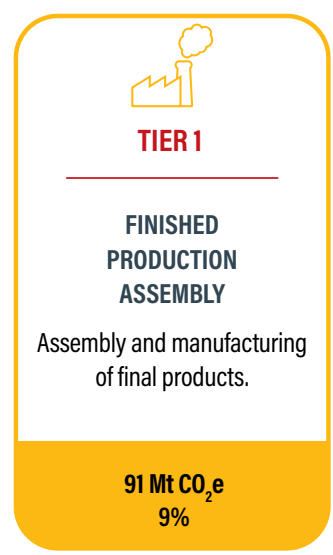

Note: 1 million tonnes $=1 \mathrm{Mt}$

Source: WRI authors. 
Table 3 compares our estimate with previous analyses.

Because all of these studies-including the Roadmap-are based on secondary data, these figures should be viewed as estimates that could be improved with better data.

Assuming business-as-usual growth for the sector, emissions are projected to be $1.588 \mathrm{Gt}$ in 2030. This reflects annual growth rates of 5 percent for synthetics and MMCF and 1 percent for cotton and other natural fibers. ${ }^{14}$
To stay within a $1.5^{\circ} \mathrm{C}$ trajectory-achieving 45 percent reduction by 2030-the sector would need to reduce emissions from $1.025 \mathrm{Gt}$ to $0.564 \mathrm{Gt}$ by 2030 . Given the business-as-usual projection to $1.588 \mathrm{Gt}$, the sector must reduce emissions by over $1 \mathrm{Gt}$ by 2030 , and even more by 2050 .

Table 3 | Comparison of GHG Emissions across Select Studies

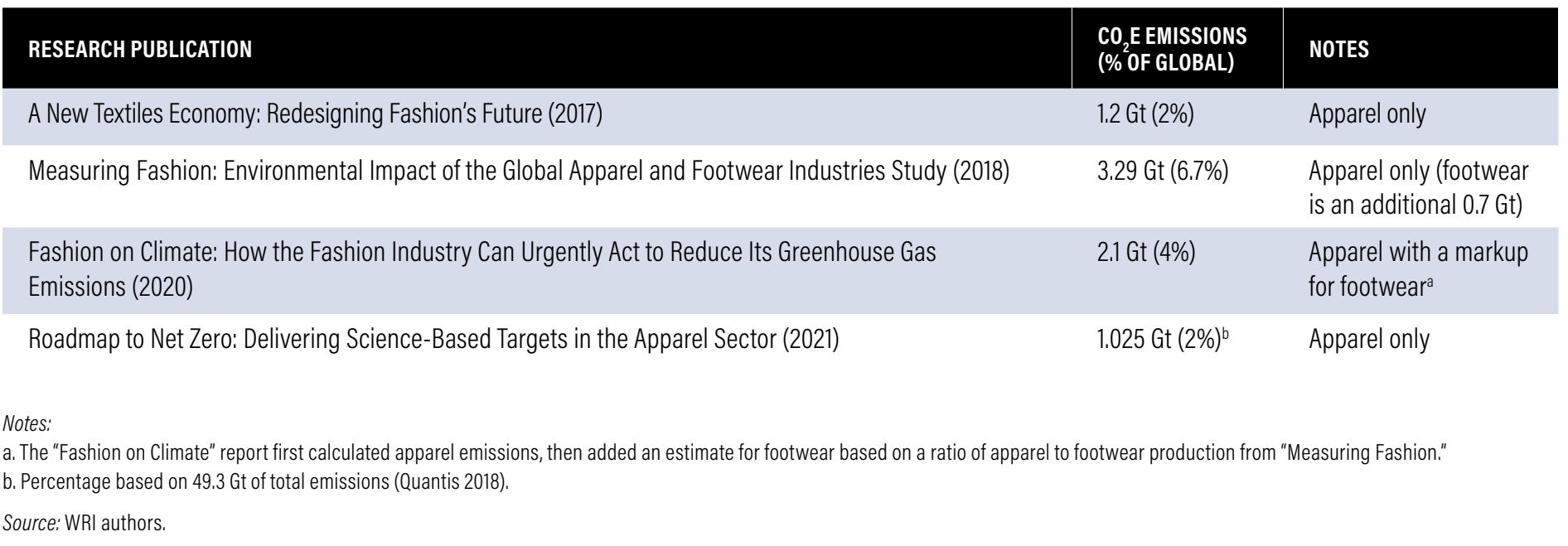

Figure 6 | Projected GHG Emissions for the Apparel Sector, 2019-2030

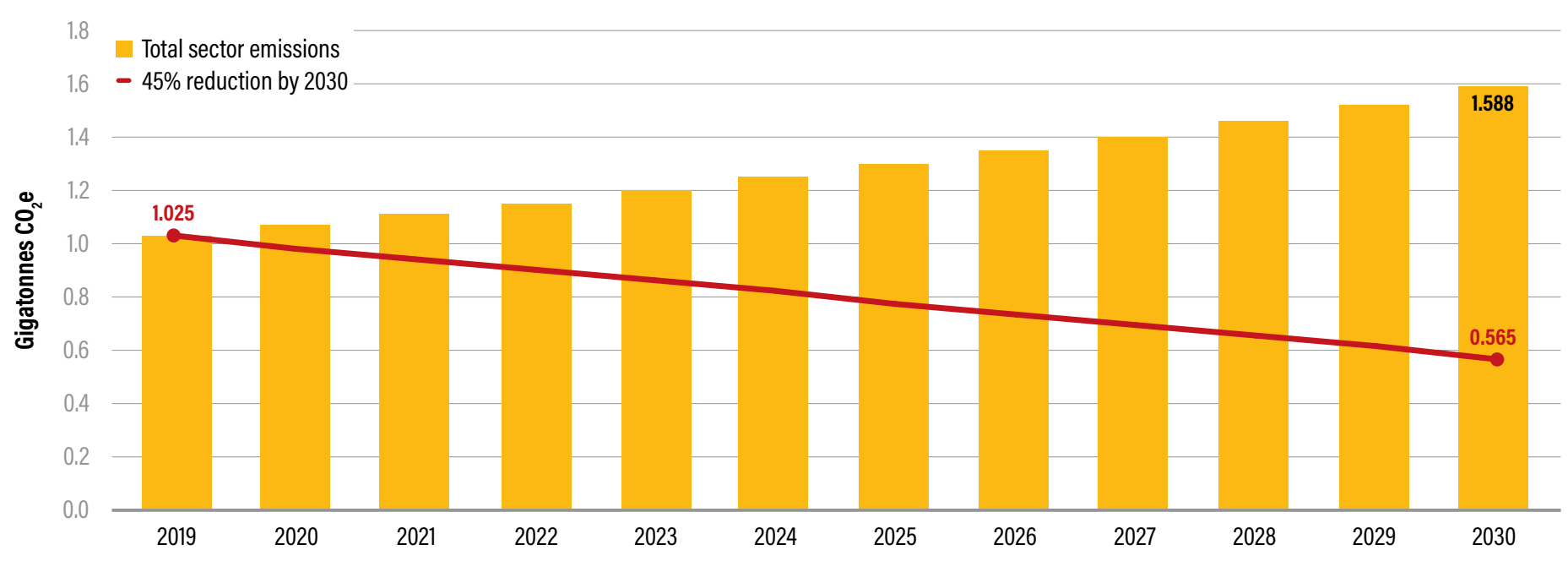

Source: WRI authors. 


\section{RECOMMENDATIONS FOR IMPROVING SECTOR GHG EMISSIONS DATA}

As described above, currently available GHG impact data is useful for estimating apparel sector emissions and identifying hotspots, but it is not robust enough to provide a definitive total emissions figure for the industry. Developing such data will require a significant investment of time and resources. We offer the following recommendations to enable this:

\section{Use the Higg FEM to increase the quality of primary data. Ultimately, high-quality primary} data is necessary in order to calculate company and sector emissions. For the apparel industry, the FEM is the most comprehensive source of primary data for tier 1 facilities, and it is increasingly being used to gather data from tier 2 and can be extended to tier 3. Prior to the FEM, brands would gather data from multiple facilities-a process that is inefficient and time consuming. The FEM allows a single manufacturer to share data with multiple customers. With regular, annual participation in the FEM process and increased verification, the quality of data will continue to improve. ${ }^{15}$

- Continue to engage companies across the value chain on measuring GHG emissions and setting SBTs. To date, the vast majority of apparel companies with approved SBTs are brands and retailers, and purchased goods and services (PG\&S) all of the emissions that result from making apparel products, from raw materials to finished goods-is the main source of their emissions. Improving data on PG\&S will require more robust measurement from the many entities comprising these PG\&S emissions, and brands, retailers, and industry associations such as the SAC and Textile Exchange can help provide support and tools.

Continue to expand and improve the MSI. All impact models rely on a mix of primary and secondary data. For the MSI, primary data used to model finished material impacts includes specific processing choices along with transportation modes and distances. Current process data can therefore only show the impact results of decisions at an aggregate industry-level process. Until the industry has more complete primary data, it will continue to rely on secondary data for estimating emissions for materials and supply chain processes.

\section{REDUCING EIMISSIONS IN THE APPAREL SECTOR}

Below are six interventions that the sector can make to reduce emissions, presented alongside barriers and potential solutions. We also provide an estimate for GHG savings from each intervention where possible. ${ }^{16}$ As with the GHG calculation presented in Section 5, the estimated reductions are based on imperfect data and thus should be viewed as directional.

\section{Figure 7 | Key Interventions for Reducing Emissions towards Net Zero}

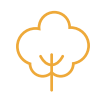

TIER 4

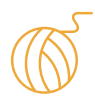

TIER 3

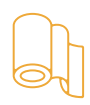

TIER 2

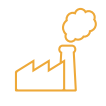

TIER 1

\section{Maximize material efficiency}

2 Scale sustainable materials and practices

3 Accelerate development of "next gen"

materials

4 Maximize energy efficiency

5 Eliminate coal in material and product manufacturing 


\subsection{Maximize Material Efficiency (Tiers 1-4)}

Through design, material selection, and methods of manufacturing, companies can reduce the amount of material that goes to waste. In effect, this minimizes the GHG emissions going into the production of raw materials, for example, by requiring less cotton to make the same amount of products. This has ripple effects across the value chain. For instance, with higher material utilization in cut and sew, less yarn would need to be spun, less fabric would need to be dyed and finished, and so on.

\section{GHG Reductions}

According to our analysis, the ratio of raw material ending up in the final product for polyester and cotton is roughly 65 percent. Assuming that an increase in material efficiency means fewer raw materials need to be grown or made, then a rough way to estimate the GHG emissions reduction is to measure the impact of producing fewer raw materials. Accordingly, if we increased the fiber to product ratio by 10 percent ${ }^{17}$ for all fiber types, emissions would be reduced by $24 \mathrm{Mt} \mathrm{CO}_{2} \mathrm{e}$.

\section{Barriers and Solutions}

Increasing material efficiency is limited by existing manufacturing processes. For example, shirts are constructed by cutting pieces from rolled textiles and sewing them together, inevitably leaving scrap. There are technical limitations to the recycling of scrap. Mechanically recycled scrap, for instance, can only be used in new fabric at low percentages for quality reasons.

While materials are a significant portion of the cost of producing a garment, missing or misaligned incentives across the value chain often hinder efforts to maximize efficiency. For example, product designers do not typically see the upstream implications of their design choices, and manufacturers can often more cheaply dispose of or downcycle textile waste than recycle it back into apparel.

Emerging technologies like 3-D sampling and production can be used to manufacture certain types of apparel with less waste. Pattern efficiency can also be improved through the use of computer-aided design tools. Training designers about the upstream implications of their choices is important, as is engaging other company functions that have some influence over materials sourcing.

\subsection{Invest in and Scale Sustainable Materials and Processes (Tier 4)}

In our analysis, the cultivation and extraction of raw materials represented $241 \mathrm{Mt} \mathrm{CO}_{2} \mathrm{e}$ (24 percent of total value chain emissions). Polyester had the most emissions at $98 \mathrm{Mt} \mathrm{CO}_{2} \mathrm{e}$, while cotton was second at $32 \mathrm{Mt} \mathrm{CO}_{2} \mathrm{e} .{ }^{18}$

One key way to reduce emissions of raw materials is to increase the use of preferred or sustainable materials. Textile Exchange defines a preferred material as "one which results in improved environmental and/or social sustainability outcomes and impacts in comparison to conventional production" (2020b). For the purposes of this publication, sustainable materials are those with lower GHG emissions on a per unit basis compared with conventional alternatives, such recycled versus virgin polyester.

\section{GHG Reductions}

Below are several potential GHG reductions from shifting to select sustainable materials by 2030, all based on MSI data. ${ }^{19}$ There will be significant challenges to reaching these percentages, but the projections allow the reader to see what is possible from material substitution. Increasing the use of these materials could also have negative side effects; for example, increasing organic cotton could require more land due to lower yields.

Mechanically recycled polyester from 15 percent to 30 percent: 23 million tonnes $\mathrm{CO}_{2} \mathbf{e}$

Chemically recycled polyester from o to 30 percent: 9.7 million tonnes $\mathrm{CO}_{2} \mathrm{e}$

Recycled nylon from $<1$ percent to 3 percent: 1.4 million tonnes $\mathrm{CO}_{2} \mathrm{e}$

Organic cotton from $<1$ percent to 3 percent: 364 thousand tonnes $\mathrm{CO}_{2} \mathrm{e}$

- Recycled cotton from $<1$ percent to 3 percent: 892 thousand tonnes $\mathrm{CO}_{2} \mathrm{e}$

Shifting from conventional viscose to 20 percent viscose made with fibers from sustainable sources: ${ }^{20}$ 3.2 million tonnes $\mathrm{CO}_{2} \mathrm{e}$

The sum of these material substitutions is 39 million tonnes $\mathrm{CO}_{2} \mathrm{e}$. 
Companies use fibers for specific product types and functionality (for instance, polyester for athletic apparel), and thus replacing one material type with another may not be straightforward. However, there are tier 4 impact differences across materials. For example, polyester has a roughly 50 percent higher MSI GHG impact score than conventional cotton. Given the significant growth in synthetic fibers over the last several decades compared with cotton-roughly 5 percent versus 1 percent, respectively, since 1990-the mix of polyester to cotton fiber has had a meaningful impact on raw material emissions.

\section{Barriers and Solutions}

While each material type has its own barriers to scale, they share common elements:

Cost. Preferred materials often cost more than conventional alternatives, and most brands and retailers are not willing to spend more on them.

Availability. Even if costs were equal, the supply of certain preferred materials is constrained. For example, according to preferred fiber and materials reports from Textile Exchange, recycled polyester (rPoly) has accounted for between 11 percent and 16 percent of total polyester production for roughly the last decade.

Quality. The quality of certain preferred materials does not currently allow for broad use in apparel. For instance, mechanically recycled cotton does not have the same properties as conventional cotton and can thus only be used in small percentages.

In addition to these barriers, some preferred materials have environmental and social implications beyond GHG emissions. rPoly, for example, may shed microfibers at a higher rate than conventional polyester.

Until the price differential between conventional and preferred materials narrows, it will be challenging for apparel companies to increase their use of preferred materials. Some companies absorb the cost differential as part of their commitments to sustainable materials. If they can purchase preferred materials in significant volumes, then the cost difference can be spread across products
B0X 7.1 | Increasing the Supply of Recycled Polyester

Virtually all recycled polyester used in apparel today comes from recycled PET bottles, and the supply of these bottles is constrained by increasing competition for bottles from other sectors (such as beverages) and import restrictions of rPET, including those from China.

While textile recycling will help meet the growing demand from apparel brands for rPoly in the future, rPET from bottles will continue as the main source of supply-and this needs to increase. A key way to achieve this is to increase PET recycling rates, which remain low in many countries. To illustrate, in a study of PET recycling rates in six Southeast Asian countries (Indonesia, Malaysia, Myanmar, the Philippines, Thailand, and Vietnam), consultancy GA Circular found that only 26 percent of PET bottles were collected for recycling in 2018, while 26 percent went to landfill and 48 percent leaked into the environment.

Note: Study of PET recycling detailed in GA Circular 2019.

Source: WRI authors

and minimized. Other companies have experimented with central pools of funding to cover price differentials so that product teams are not penalized for choosing sustainable materials.

Increasing the supply of rPET can be done by increasing recycling rates in source countries, getting more rPET into these countries (for instance, cleaning up imported plastic bales), and advancing technology processing to include a wider range of PET bottles, such as colored plastic. Apparel companies can engage policymakers to help increase recycling rates and enact other measures to advance sustainable materials.

The quality of preferred materials can be improved so they can be used in more applications and in higher volumes. For example, the use of recycled cotton has been limited due to quality issues, though companies like Patagonia are making products with higher percentages of recycled cotton. 


\section{Box 4 | Reducing GHG Emissions in Conventional Cotton Production}

Using sustainable fibers is key to helping brands meet their SBTs and other sustainability goals. Currently, approximately 25 percent of global cotton production is considered to be preferred, yet all cotton producers will need to reduce emissions for the sector to deliver on its climate commitments. Regardless of the production system (organic or conventional) or preferred fiber program (such as the Better Cotton Initiative or the U.S. Cotton Trust Protocol), the levers for cotton to reduce GHG emissions are generally the same.

- Input efficiency. Field emissions (namely, the release of nitrous oxide), fertilizer production, and irrigation are significant sources

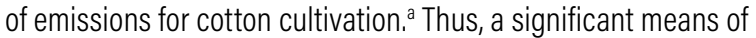
reducing the GHG footprint of cotton is to be more efficient with inputs like fertilizer and irrigation water.

- Energy efficiency and renewable energy. Increasing energy efficiency and deploying renewable energy for key processes such as ginning and irrigation can reduce GHG emissions in cotton production. This is expanded upon in a study from Funk and Hardin on gin efficiency, for instance. ${ }^{b}$

- Regenerative growing practices. Regenerative agriculture refers to practices that improve soil health by restoring soil's organic carbon, including, for instance, conservation tillage, the use of cover crops, and crop rotation. It is generally agreed that regenerative agriculture practices improve soil health and other environmental outcomes. For example, no-till reduces erosion and water runoff. There are different perspectives about the potential for regenerative agriculture to reduce GHG emissions. In a 2020 paper, WRI raises questions about the GHG reduction potential of regenerative agriculture, including, for example, the permanence of stored carbon, additionality in the reductions, and the need for nitrogen to be added to fix the carbon in the soil. ${ }^{c}$ However, other organizations have presented data on the GHG benefits of conservation tillage, from both carbon sequestration and reduced fuel consumption. It is beyond the scope of this paper and the expertise of the authors to go deeper into the potential climate benefits of regenerative agriculture, but the sector should further explore this in future analysis.

Notes:

a. Cotton Incorporated 2017

b. Funk and Hardin 2012.

c. Ranganathan et al. 2020 .

Source: WRI authors.

\subsection{Accelerate the Development of Next Generation Preferred Materials (Tier 4)}

Even with notable increases in preferred materials, there remains a significant innovation gap to reduce emissions in line with SBTs. The sector needs to significantly increase its investment in "next generation" preferred materials. This includes, for example, textile-to-textile recycling, plant-based leather, materials made with carbon dioxide, and others. Textile Exchange's PFMMR (2020a) cites a number of these materials across fiber types. These include, for example:

Circular Systems BioFibre ${ }^{\mathrm{TM}}$ : fiber made from food crop residues

Recycleather ${ }^{\mathrm{TM}}$ : 60 percent recycled leather and 40 percent vegetable and synthetic products

- yylo $^{\mathrm{TM}}$ : leather-like material developed from mycelium cells

- NuCycl $^{\mathrm{TM}}$ : fabric made from discarded clothing and textile waste

SAYA: GRS-certified chemically recycled PET

Genomatica: 100 percent biobased caprolactam, a precursor to nylon

\section{GHG Reductions}

Most next generation materials are in the early stages of development, and thus GHG data is not readily available. Rough GHG estimates can be made at lab scale but it is difficult to project the impacts at commercial scale as parameters will change. For example, commercial scale may require operating a facility in a location with a different energy mix than the lab location. To ensure that the substitution of these materials results in GHG emissions reductions, it will be critical to accurately measure their GHG impacts.

\section{Barriers and Solutions}

As with existing preferred materials, next generation materials need to compete with conventional versions on cost, or deliver performance, quality, or other benefits that justify any price premium. Next generation materials also require the following: 
Research and development. Developing materials to meet all material and product specifications, including quality, functionality, and cost.

\section{Application development. Material innovators} need support from manufacturers and brands to finetune their materials for different product applications.

Brand commitment. For these materials to scale, brands need to commit to buying them. Offtake agreements-a company agreeing in advance to purchase the output of a manufacturer-are not as common in the apparel industry as they are in other sectors. For example, L'Oreal has an offtake agreement with Loop Industries for chemically recycled PET (Loop Industries, Inc. 2020).

Integration into the apparel supply chain. These materials must be integrated into global supply chains. Cotton recycling technology, for instance, might be placed across tiers 1 to 3 so each can recycle waste within the respective tier.

\subsection{Maximize Energy Efficiency across Apparel Manufacturing (Tiers 1-3)}

There are opportunities to reduce energy consumption through efficiency across tiers 1 through 3 . The magnitude of the potential reductions is facility-dependent; for example, factories that have already invested in energy efficiency will have less potential reductions. Also, certain processes may be more ripe for efficiency gains than others, like dyeing as compared to spinning.

\section{GHG Reductions}

According to our research and expert interviews, energy efficiency efforts in tier 1, 2, and 3 facilities can result in energy and emissions savings of up to 15 percent per unit (garment, fabric, or yarn). If we assume an energy efficiency improvement of 15 percent per unit, the potential reductions are $64 \mathrm{Mt} \mathrm{CO}_{2}$ e between 2019 and 2030. See Appendix E for a case study on Clean by Design.

Energy efficiency is a key first step, as it is a readily available intervention that has a positive return on investment. However, absolute emissions may increase as production volume increases. This is why shifting from coal to lowercarbon alternatives for thermal energy and moving to 100 percent renewable electricity are vital to decarbonizing the apparel sector.

\section{Barriers and Solutions}

If energy is inexpensive, investing in efficiency will tend to have a lower return and longer payback compared with other investments. Also, companies may lack the necessary in-house technical expertise to identify and implement efficiency opportunities or resources to hire external experts.

Manufacturers may not have the capital to invest in efficiency and new equipment. Brands are generally not willing to fund efficiency or make long-term purchase commitments to help pay off investments. This presents a dilemma for manufacturers: they could invest on their own to make improvements, but their customers may take their business elsewhere, thus "stranding" the investment. This brand-manufacturer dynamic will need to change in order for efficiency efforts to accelerate. For example, brands may need to commit to longer-term relationships so that manufacturers have the required certainty to invest.

Some manufacturers have reported that banks may be hesitant to lend money for efficiency investments given the long payback period, and banks generally prefer to lend money for projects that increase revenue (like factory expansions). That said, a recent WRI paper found that a growing number of banks are committing to shift their portfolios to net-zero emissions by 2050 to align with the objectives of the Paris Agreement (Waslander et al. 2021).

To address the need for investment in efficiency, brands, manufacturers, and others might create a fund for financing energy efficiency. The fund could be managed by a financial institution and backed by the companies contributing to the fund. The contributions could be treated as principal from each company that is returnable with any share of efficiency gains. The fund duration would be long enough to allow for manufacturers to see the payback from their investments.

Companies could also collaborate to support academic institutions to develop training programs in key manufacturing countries on energy- and environment-related skill sets. These institutions might be local or international. Arizona State University's partnership with the Vietnamese Ministry of Science and Technology offers one example (ASU 2017). 


\subsection{Eliminate Coal in Textile Mills and Manufacturing Facilities (Tiers 1 and 2)}

Coal is a commonly used fuel in textile mills and other manufacturing facilities for thermal processes such as heating water for dyeing fabric and generating steam. While there is no definitive figure for the amount of coal used in textile mills globally, thermal energy is the majority energy form (upwards of 75 percent, according to our conversations with industry experts).

\section{GHG Reductions}

Without access to primary data on coal consumption for thermal energy, it is impossible to definitively state the potential extent of emissions reductions from switching from coal to other fuel sources for thermal energy. FEM data should help with this analysis in the future.

Using the emissions from our calculation, we can put rough dimensions on the reduction opportunity. Assuming that 75 percent of tier 2 emissions $\left(536 \mathrm{Mt} \mathrm{CO}_{2} \mathrm{e}\right)$ are from combustion for thermal energy, and 50 percent of that is from coal, then shifting half of this coal to a carbon-free energy source would reduce emissions by 100.5 Mt $\mathrm{CO}_{2} e^{21}$

For tier 1 ( $91 \mathrm{Mt} \mathrm{CO}_{2} \mathrm{e}$ ), if 20 percent of emissions are from combustion for thermal energy and 50 percent of that is from coal, then shifting to a carbon-free energy source would reduce emissions by $4.6 \mathrm{Mt} \mathrm{CO}_{2} \mathbf{e}^{22}$

In total, shifting 50 percent of coal used for thermal energy in tiers 1 and 2 to a carbon-free source would reduce emissions by a total of $105 \mathrm{Mt} \mathrm{CO}_{2} \mathbf{e}$.

\section{Barriers and Solutions}

Coal is cheap and plentiful in a number of apparelmanufacturing countries, and it is a good fuel source for thermal energy. Alternatives to coal thus face a high barrier to entry, especially without pressure from regulators, customers, or other stakeholders. Combustion of natural gas emits over 40 percent less carbon dioxide $\left(\mathrm{CO}_{2}\right)$ than coal does (EIA 2020), but it may be unavailable or too expensive depending on the country. Biomass may result in lower GHG emissions, but this depends on a number of factors, including the nature of the crop being used, how much carbon it sequesters before harvest, and whether the biomass is additional (in other words, biomass above what is already being grown). Sustainable supplies of biomass may not be available in certain countries, and biomass may have other implications. For example, cultivating it could displace food with fuel crops. For an overview of the potential and challenges of biomass as an energy source, see WRI's “Avoiding Bioenergy Competition for Food Crops and Land" (Searchinger and Heimlich 2015).

Unlike other interventions that have known and ready solutions, replacing coal for thermal energy is more challenging. While gas and biomass could be bridge fuels to zero carbon alternatives, there are no readily available zero carbon energy sources. Some companies are exploring electrification of thermal processes, but not all such processes can be electrified and this would require 100 percent renewable electricity. There are technologies on the horizon that may provide an alternative for thermal energy. For example, Heliogen is developing a form of concentrated solar that uses artificial intelligence and mirrors to generate heat above $1,000^{\circ} \mathrm{C}$-well above temperatures needed for apparel production (Heliogen 2021). Companies are also exploring and using innovative manufacturing processes like waterless dyeing, which reduces the need for thermal energy. Addressing the thermal energy challenge will require investment and collaboration across the apparel sector and with other sectors.

\subsection{Shift to 100 Percent Renewable Electricity in Manufacturing (Tiers 1-3)}

While companies should aim to reduce energy consumption via energy efficiency, if they continue to increase production, absolute GHG emissions will increase over time. In addition to transitioning away from coal for thermal energy consumption, manufacturers across tiers 1 through 3 must shift to 100 percent renewable electricity for the sector to deliver on SBTs. The breakdown of energy between thermal and electricity varies by tier, with tier 3 nearly all electricity, tier 2 mostly thermal, and tier 1 mostly electricity.

\section{GHG Reductions}

Modeling actual emissions reductions from shifting to renewable electricity in tiers 1 through 3 would require analysis at the individual facility level for thousands of facilities. This is a significant undertaking, but something the Higg FEM can be used for in the future. 
As a proxy, based on our approach using MSI data, a 50 percent shift to renewable energy in spinning, textile formation, and finished goods assembly would reduce emissions by an estimated 213 Mt. A 100 percent shift would reduce emissions by $424 \mathrm{Mt}$.

\section{Barriers and Solutions}

As a starting point, a facility needs to be located in a region with sufficient renewable electricity resources. Solar and wind resource maps like the Global Solar Atlas show the potential for these forms of energy across countries. Other forms of low-carbon power generation such as geothermal, nuclear, and small hydropower can also play a meaningful role in some geographies.

On-site renewable energy is often limited by space: there is a limit to the number of solar panels that can be installed on a factory roof or property. Facilities also need to be structurally suitable to host the panels. Investments in on-site renewables face similar challenges to those outlined above for energy efficiency.

To supplement on-site renewables, companies will need to procure renewable energy from off-site sources, either directly from utility programs or via renewable energy products such as power purchase agreements (PPAs) and renewable energy certificates (RECs). For off-site procurement, the regulatory environment may not allow companies to purchase renewable energy. For example, electricity market regulations in some Indian states prohibit or limit companies' ability to purchase electricity from sources other than the utility, while off-site PPAs are not yet available in Vietnam (though the apparel and other sectors are working with the Vietnamese government on a pilot program for off-site solar and wind PPAs). Where off-site renewable electricity procurement mechanisms are available, contracts may be too long in duration, as factories with customers shifting every few years may be at risk if they are bound to 10- or 20-year contracts.
In some countries and contexts, on-site solar is economically viable, and some countries are creating a supportive regulatory environment for on- and off-site renewables. For example, a feed-in tariff and net billing mechanism in Vietnam has accelerated solar capacity from o to nearly 20 gigawatts peak (GWp) in a little more than two years, including close to $10 \mathrm{GWp}$ of rooftop solar.

Ultimately, a decarbonized electric grid will be the strongest lever to reduce emissions associated with electricity consumption in apparel manufacturing. Companies, individually and collectively, can play a meaningful role in advocating to national government and utility companies that rapid grid decarbonization is essential.

\subsection{Tallying the Reductions}

If the apparel industry deployed the above interventions, total emissions reductions could amount to 656 million tonnes $\mathrm{CO}_{2} \mathrm{e}$.

\section{Table 4 | Emissions Reduction for Each Intervention}

\begin{tabular}{|l|l|}
\hline INTERVENTION & $\begin{array}{l}\text { EMISSIONS REDUCTIONS } \\
\text { (MILLION TONNES CO} \mathbf{2}_{\mathbf{2}} \text { ) }\end{array}$ \\
\hline Maximize material efficiency & 24 \\
\hline $\begin{array}{l}\text { Invest in and scale sustainable materials } \\
\text { and processes }\end{array}$ & 39 \\
\hline $\begin{array}{l}\text { Accelerate the development of next } \\
\text { generation materials }\end{array}$ & Unknown \\
\hline $\begin{array}{l}\text { Maximize energy efficiency } \\
\text { Eliminate coal in textile mills and } \\
\text { manufacturing facilities }\end{array}$ & 64 \\
\hline $\begin{array}{l}\text { Shift to } 100 \text { percent renewable electricity } \\
\text { in manufacturing }\end{array}$ & 105 \\
\hline \begin{tabular}{l} 
Total \\
\hline
\end{tabular} & 424 \\
\hline
\end{tabular}

Note: This figure represents a shift to 50 percent zero carbon fuel for thermal processes by 2030. A shift to 100 percent would reduce emissions by $210 \mathrm{Mt}$.

Source: WRI authors. 


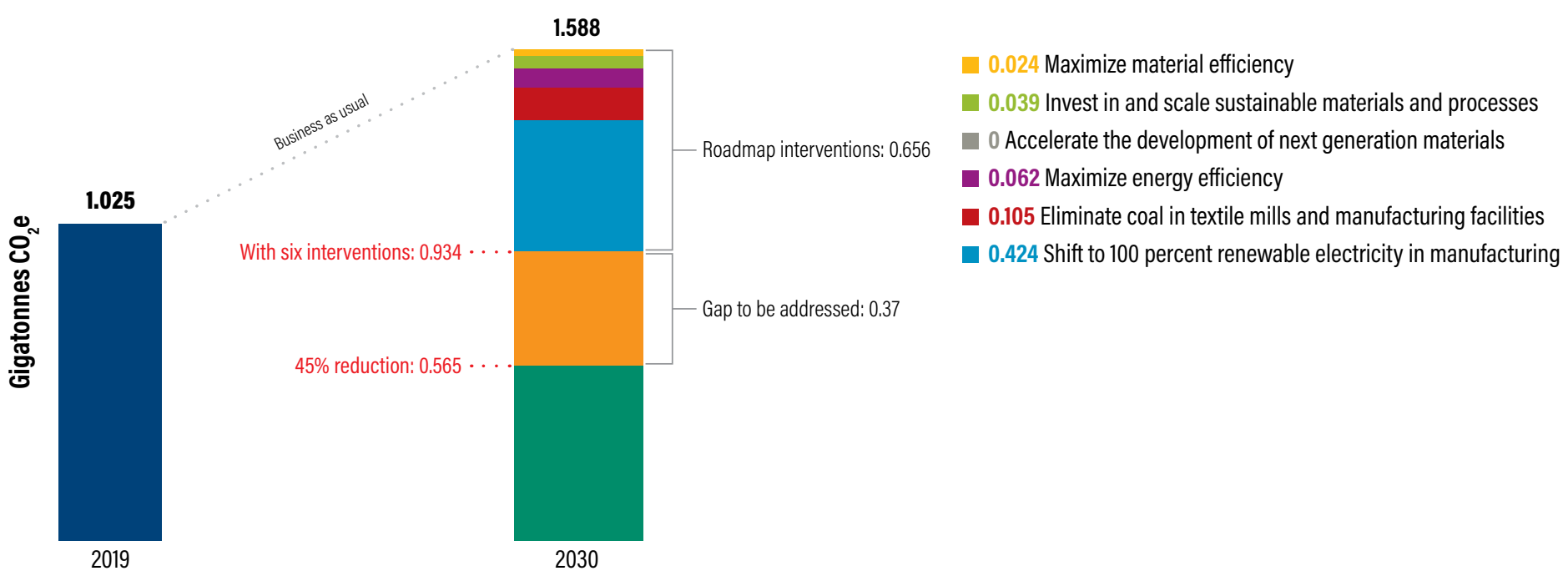

Note: We do not have data for emissions reductions for next generation materials (number 3).

Source: WRI authors.

\section{SPOTLIGHT ON THE CIRCULAR ECONOMY}

Given the magnitude of emissions reductions needed to stay within a $1.5^{\circ} \mathrm{C}$ pathway, it is clear the apparel industry needs to decouple revenue growth from emissions growth. One emerging way to do this is through circular products, processes, and business models.

\subsection{Overview}

The concept of the circular economy has received considerable attention in the apparel industry in recent years. The topic has its origins in frameworks and concepts such as industrial ecology, design for environment, and cradle-to-cradle design. The Ellen MacArthur Foundation (EMF) has elevated awareness of the concept, synthesizing the above and other frameworks under the concept of circular economy:

The circular economy is restorative and regenerative by design. Relying on system-wide innovation, it aims to redefine products and services to design waste out, while minimizing negative impacts. Underpinned by a transition to renewable energy sources, the circular model builds economic, natural, and social capital (EMF 2015). 
Figure 9 | Circular Economy Framework

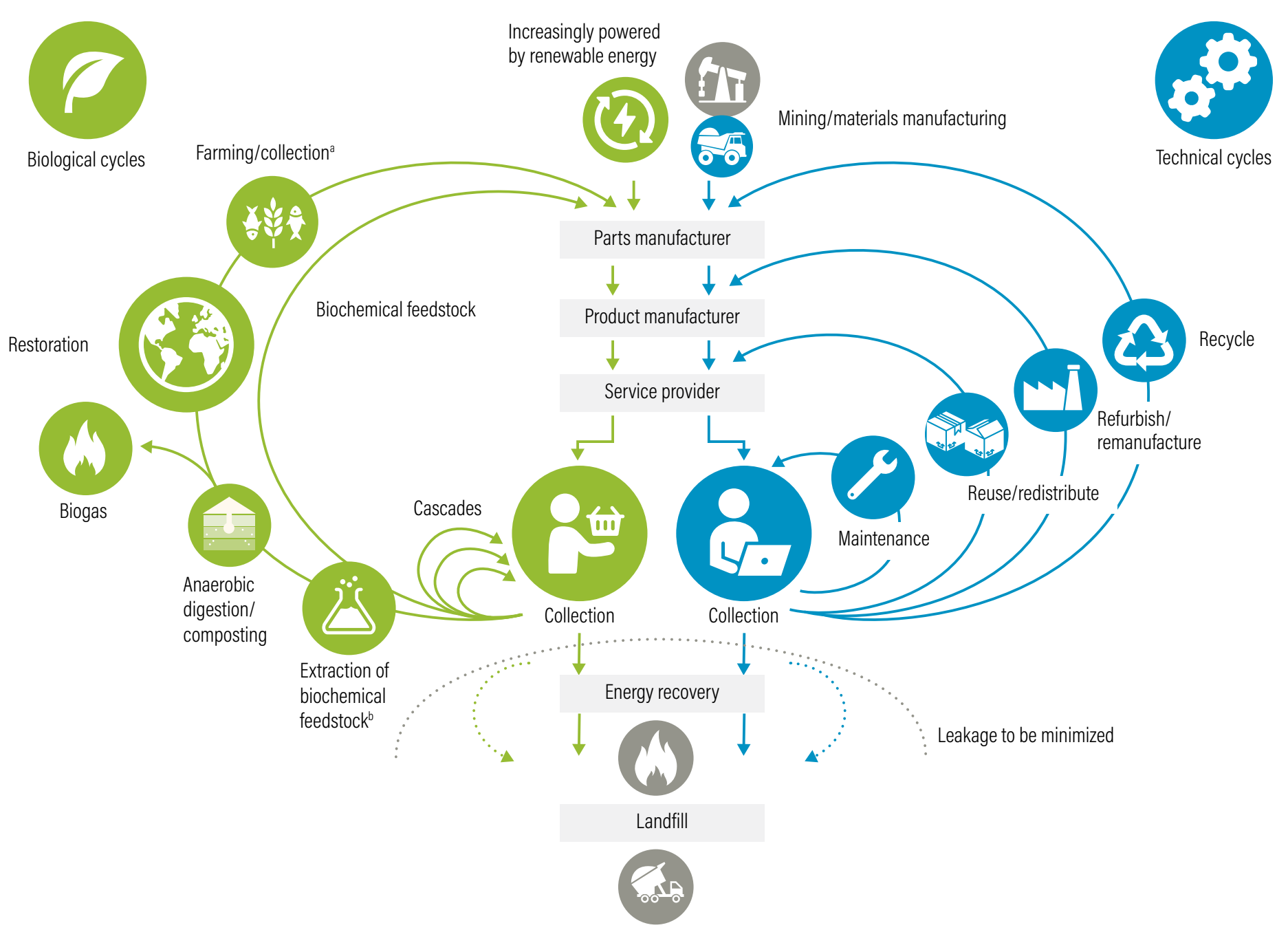

Notes:

a. Hunting and fishing

b. Can take both post-harvest and post-consumer waste as an input

Source: Adapted from EMF 2015.

\subsection{Circular Economy in the Apparel Sector}

As illustrated in Figure 9, the circular economy is multifaceted and relevant across the value chain. Section 7 described how shifting to sustainable materials and improving material efficiency can reduce emissions. The Roadmap also describes how companies can reduce emissions through more efficient and innovative manufacturing practices. Dope dyeing of synthetic fibers, for instance, results in over 90 percent fewer emissions than batch dyeing. Apparel companies are also exploring novel, circular business models. While most are relatively small in terms of revenue, companies offering reuse, rental, and repair show promise for reducing emissions, but on-the-ground impact data is still needed. 


\subsection{GHG Implications of Circular Business Models}

For the purposes of this paper, alternative business models are defined as those differing from the traditional, linear model. For example:

Refurbishment. The Renewal Workshop works with brands to refurbish and sell excess inventory and unsellable inventory (Renewal Workshop 2021).

Repair. As part of its Worn Wear program, Patagonia repairs products and offers used products for sale (Patagonia 2021a).

Rental/Subscription. Rent the Runway allows members to rent four or more items at a time and swap these items at any time (Rent the Runway 2021).

Resale. Zalando's Zircle allows consumers to buy and sell pre-owned clothes. This is a key piece of Zalando's strategy to extend the life of at least 50 million products by 2023 .

Several researchers have suggested that extending the useful life of a garment-a feature of the above models-reduces life cycle GHG impacts. For example, Mistra Future Fashion found that doubling the lifespan of a garment (30 to 60 uses) reduced its GHG footprint by roughly half (Roos et al. 2019). Similarly, EMF found that doubling the average number of times a garment is worn reduces emissions by 44 percent (Morlet et al. 2017).

Intuitively, these findings make sense: making products more durable so that consumers buy fewer of them should reduce environmental impacts. However, these studies are based on consumer surveys, not actual behavior. If a shirt lasts twice as long due to better materials and construction, does this mean a consumer does not buy a second shirt (or a third)? While measuring this displacement rate is challenging, companies can be bolder in communicating to consumers the potential environmental impact of purchasing fewer new products.

For additional perspectives and guidance on circular business models, see WRI's paper Square Your Circle (Drew et al. 2021).

\subsection{Advancing the Circular Economy in Apparel}

A number of challenges will need to be addressed for the circular economy to scale in apparel:

The low cost of fast fashion. In general, circular business models benefit from higher quality materials and products that last longer and are worth repairing, renting, and reselling.

Consumer attitudes and behaviors. While a segment of consumers use businesses such as Rent the Runway and ThredUp, the vast majority of consumers continue to purchase new apparel. This is likely due to a combination of factors, including consumer preference (for new items, specific styles, and price points), brand marketing, and predisposition for purchasing apparel via conventional channels.

Lack of infrastructure. Related to the shift of the apparel industry towards fast fashion, there is a lack of infrastructure to support circular business models in many countries. For example, in the past, the United States had more repair shops, allowing consumers to keep their clothing in use for longer.

State of recycling technology. While there is a growing number of companies with promising textile recycling technologies, many of these are in lab or precommercial scales and have limitations (for instance, in processing blended fabrics).

Geographically dispersed and complex value chains. As recycling technologies mature, the industry needs to determine how to get the recycled material to the right point in a far-reaching, global value chain. For example, cotton may be grown in one country, spun into yarn in another, made into fabric in another, and so on.

\section{Government regulations on the flow of}

waste. A core aspect of the circular economy is the reutilization of waste across the value chain, and government policies can shape this. For example, there are often restrictions on the flow of waste materials across national borders, thus a company with the ability to recycle textile scrap based in one country may not be able to import scrap from another.

For additional perspectives on the potential benefits of reuse business models and guidance for companies to shift to such models, see WRI's Square Your Circle report (Drew et al. 2021). 
9 CALL TO ACTION

According to the United in Science 2021 report released in September 2021, global GHG emissions continue to rise-despite the COVID-19 pandemic-and there is a growing likelihood that temperatures will temporarily exceed the threshold of $1.5^{\circ} \mathrm{C}$ above pre-industrial levels in the next five years (WMO 2021). Rising temperatures are fueling a variety of environmental and economic impacts, from heatwaves and fire in locations such as Greece, Siberia, Turkey, and the United States, to flooding in China, Germany, and elsewhere. In a foreword to the above report, United Nations Secretary-General Antonio Guterres said, "Unless there are immediate, rapid, and large-scale reductions in greenhouse gas emissions, limiting warming to $1.5^{\circ} \mathrm{C}$ will be impossible, with catastrophic consequences for people and the planet on which we depend" (WMO 2021).

To stay on pace with the $1.5^{\circ} \mathrm{C}$ pathway, the apparel sector must significantly step up its efforts to reduce GHG emissions. To do so, we call upon the industry and individual companies to take the following actions:

Collaborate to improve sector GHG impact data. As described above, the quality of GHG emissions data for activities across the apparel value chain needs improvement. Companies should work together and with organizations such as Textile Exchange and SAC to improve existing data sets. Brands should work with manufacturers to gather and share more robust primary data via platforms like the Higg FEM. Material suppliers can measure the GHG emissions from the creation of their materials and contribute their data to the Higg MSI. Better data will make reports such as this one more accurate in the future. That said, the current state of data does not prevent the sector from taking bold action now.

\section{Ramp up efforts on manufacturing energy effi-} ciency. Based on its work with apparel manufacturers, Aii sees a tremendous opportunity to make textile and apparel production more energy efficient -15 to 50 percent per unit depending on the facility-and to reduce costs. Manufacturers will invest in energy efficiency when they see a clear business case, and this would be supported if brands committed to purchasing materials and products from more efficient manufacturers. Energy efficiency is a well-established opportunity, and companies can join existing programs such as Aii's Mill Impact Initiative (Aii 2021a) and leverage public resources such as adidas' Environmental Good Practice Guide \& Toolkit (adidas 2019).

Invest in and incentivize renewable energy in the supply chain. Electricity from solar and wind is increasingly cost competitive, and the barriers are generally less about the technology and more about the needed capital investment and the regulatory environment. Organizations such as the Clean Energy Investment Accelerator are working to advance renewable energy in key manufacturing countries in a variety of ways, including driving joint purchases. Companies such as VF Corporation, Far Eastern New Century, and H\&M are issuing green bonds to support investment in projects including renewable energy. The sector needs more of such investment to decarbonize the electricity-related facets of the value chain, and it needs companies to incentivize suppliers to shift to 100 percent renewable energy.

\section{Scale up the use of sustainable materials and} processes. Brands should commit to using a higher percentage of sustainable materials like those identified in Textile Exchange's Preferred Fiber and Material Matrix (Textile Exchange 2021). While some may cost more, greater demand across brands can drive down unit costs and send a signal to material suppliers to increase production. Brands should also work with material suppliers to identify other ways to reduce emissions at the raw materials phase, such as the opportunities suggested by Cotton Incorporated and cited above.

\section{Invest in research and development for next generation materials and solutions for thermal} energy. Unlike interventions like energy efficiency that are ready to be deployed, the industry will need to invest in developing next generation materials and to find alternatives to coal for thermal energy. Individual companies and small groups of companies are working on such solutions, but significantly more investment is needed to bring these to scale faster. While materials are generally competitive, thus limiting collaboration, the sector should band together and boost investment to find alternatives to coal.

\section{Address the elephant in the room: consumption.}

Even if the sector is able to take on the above actions, it will still face a gap in reducing emissions and continue to have other impacts, including pre- and post-consumer waste. It is encouraging to see the proliferation of business models that aim to decouple revenue from selling more new products-but we need more of these models at scale. 


\section{APPENDIX A: ORGANIZATIONS WHICH PROVIDED FEEDBACK ON THE FIRST DRAFT}

Individuals from the following organizations completed a feedback survey on the first draft of the Roadmap published in September 2020.

Bestseller

Connective Impact

Cotton Incorporated

EcoAct

Epic Designers Ltd

Gap, Inc.

Higg

TAL Apparel Ltd

Target Corporation

United States Cotton Trust Protocol

World Wide Fund for Nature
In addition to these entities that completed the survey, we received feedback via email or phone from a variety of other organizations. 


\section{APPENDIX B: STAKEHOLDER FEEDBACK ON THE PRELIMINARY DRAFT AND KEY CHANGES}

In September 2020, we published a preliminary draft of the Roadmap to solicit stakeholder feedback on our approach and findings. The feedback period lasted through November 1, 2020, and we received verbal and written feedback from several dozen stakeholders.

There were a number of common recommendations from stakeholders:

- Provide greater transparency into the emissions calculations for each tier, including the underlying data and assumptions.

- Be more explicit about the limitations in using secondary data-in other words, MSI-for calculating an industry-wide footprint, and how to improve the calculation over time.

- Explain what portions of the industry value chain were omitted in the analysis and why.

- Project the emissions of the sector out to 2030 and more clearly identify how the sector can reduce emissions 45 percent by 2030 and to net zero by 2050.

We also received feedback on key assumptions underlying the emissions calculations across the tiers, including, for example, on the percentage of fibers used in the apparel industry. We highlight these changes throughout this report.
Compared with the first draft, the final Roadmap includes the following notable changes:

- A projection of sector emissions from 2019 to 2030

- Revised projections for material substitutions out to $2030^{23}$

- Analysis of potential GHG reductions for conventionally grown United States cotton through input efficiency and good soil management practices

- For tier 2 emissions calculations, the additional step on "additional coloration and finishing"

- Additional perspective on the potential for biomass for thermal energy needs in tier 2 


\section{APPENDIX C: FIBER AMOUNTS USED IN OUR ANALYSIS}

\begin{tabular}{|c|c|c|}
\hline FIBER TYPE & $\begin{array}{l}\text { AMOUNT FROM } 2020 \\
\text { PFMMR (THOUSAND } \\
\text { TONNES) }\end{array}$ & $\begin{array}{l}\text { AMOUNT USED IN } \\
\text { OUR CALCULATION } \\
\text { (THOUSAND TONNES) }^{\text {a }}\end{array}$ \\
\hline \multicolumn{3}{|l|}{ COTTON } \\
\hline Conventional & 19,281 & $16,404 b$ \\
\hline $\mathrm{BCl}$ & 5,206 & \\
\hline $\begin{array}{l}\text { Cotton Made in } \\
\text { Africa }\end{array}$ & 588 & 388 \\
\hline Organic & 239 & 158 \\
\hline Cleaner cotton & 0.91 & \\
\hline REEL & 63 & \\
\hline BASF e3 & 161 & \\
\hline ISCC & 137 & \\
\hline Fair trade & 6 & \\
\hline Recycled & 0 & \\
\hline \multicolumn{3}{|l|}{ WOOL } \\
\hline Sheep & 1,070 & $716 c$ \\
\hline Recycled & 22 & 14.5 \\
\hline Mohair & 4.4 & \\
\hline Cashmere & 10.4 & \\
\hline \multicolumn{3}{|l|}{ DOWN } \\
\hline Duck & 216 & 143 \\
\hline Goose & 54 & 36 \\
\hline
\end{tabular}

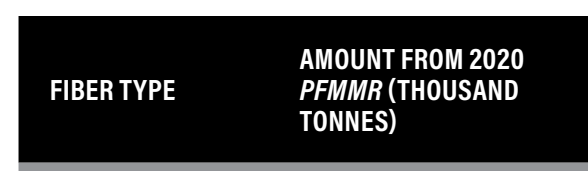

AMOUNT USED IN

OUR CALCULATION

(THOUSAND TONNES)

\begin{tabular}{lll}
\hline MMCF & & \\
\hline Viscose & 5,630 & 3,716 \\
\hline Lyocell & 300 & 198 \\
\hline Modal & 200 & 132 \\
\hline Acetate & 950 & 0 \\
\hline Cupro & 17 & 0 \\
\hline PoLYESTER & & \\
\hline Fossil-fuel based & 49,622 & 32,751 \\
\hline Recycled & 8,078 & 5,331 \\
\hline NYLoN & & \\
\hline Fossil-fuel based & 5,580 & 3,683 \\
\hline Recycled & 0 & \\
\hline Bio-based & 240 & 158 \\
\hline OTHER & & \\
\hline Acrylic & 2,775 & 1,832 \\
\hline Elastane & 850 & 561 \\
\hline Polypropylene & 2,775 & 1,832 \\
\hline Hemp & 61 & 40 \\
\hline Silk & 160 & 106 \\
\hline Flax & 868 & 573 \\
\hline
\end{tabular}

Notes:

a. All figures are based on 66 percent allocation.

b. Includes fiber types without MSI data, such as BCl and REEL.

c. Mohair and cashmere modeled with sheep wool data, since MSI data does not exist.

Sources: Textile Exchange and WRI authors. 


\section{APPENDIX D: FIBER LOSS RATES}

\begin{tabular}{|c|c|c|c|c|c|c|c|c|c|c|}
\hline \multicolumn{3}{|c|}{ FIBER } & $\begin{array}{l}\text { YARN FOR- } \\
\text { MATION }\end{array}$ & $\begin{array}{l}\text { TEXTILE } \\
\text { FORMA- }\end{array}$ & PREPARATION & $\begin{array}{l}\text { COLOR- } \\
\text { ATION }\end{array}$ & $\begin{array}{l}\text { ADDITIONAL } \\
\text { COLORATION }\end{array}$ & ASSEMBLY & $\begin{array}{l}\text { FIBER TO } \\
\text { MATERIAL }\end{array}$ & $\begin{array}{l}\text { FIBER TO } \\
\text { PRODUCT }\end{array}$ \\
\hline \multirow{5}{*}{ 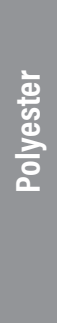 } & \multirow[t]{2}{*}{ Filament } & Knit & $3 \%$ & $7 \%$ & $4 \%$ & $6 \%$ & $1 \%$ & $20 \%$ & $82 \%$ & $66 \%$ \\
\hline & & Woven & $3 \%$ & $3 \%$ & $4 \%$ & $6 \%$ & $1 \%$ & $20 \%$ & $85 \%$ & $68 \%$ \\
\hline & \multirow[t]{2}{*}{ Staple } & Knit & $9 \%$ & $7 \%$ & $4 \%$ & $6 \%$ & $1 \%$ & $20 \%$ & $77 \%$ & $61 \%$ \\
\hline & & Woven & $9 \%$ & $3 \%$ & $4 \%$ & $6 \%$ & $1 \%$ & $20 \%$ & $80 \%$ & $64 \%$ \\
\hline & \multirow{2}{*}{ Filament } & Knit & $3 \%$ & $7 \%$ & $4 \%$ & $6 \%$ & $1 \%$ & $20 \%$ & $82 \%$ & $66 \%$ \\
\hline \multirow{3}{*}{$\frac{\overline{5}}{2}$} & & Woven & $3 \%$ & $3 \%$ & $4 \%$ & $6 \%$ & $1 \%$ & $20 \%$ & $85 \%$ & $68 \%$ \\
\hline & \multirow[t]{2}{*}{ Staple } & Knit & $9 \%$ & $7 \%$ & $4 \%$ & $6 \%$ & $1 \%$ & $20 \%$ & $77 \%$ & $61 \%$ \\
\hline & & Woven & $9 \%$ & $3 \%$ & $4 \%$ & $6 \%$ & $1 \%$ & $20 \%$ & $80 \%$ & $64 \%$ \\
\hline \multirow{4}{*}{$\frac{\text { 음 }}{\frac{2}{2}}$} & \multirow[t]{3}{*}{ Filament } & Knit & $3 \%$ & $7 \%$ & $4 \%$ & $0 \%$ & $1 \%$ & $20 \%$ & $87 \%$ & $69 \%$ \\
\hline & & Woven & $3 \%$ & $3 \%$ & $4 \%$ & $0 \%$ & $1 \%$ & $20 \%$ & $90 \%$ & $72 \%$ \\
\hline & & $\begin{array}{l}\text { Non- } \\
\text { woven }\end{array}$ & $3 \%$ & $0 \%$ & $0 \%$ & $0 \%$ & $0 \%$ & $20 \%$ & $97 \%$ & $78 \%$ \\
\hline & Filament & Knit & $3 \%$ & $7 \%$ & $4 \%$ & $6 \%$ & $1 \%$ & $20 \%$ & $82 \%$ & $66 \%$ \\
\hline \multirow{3}{*}{$\frac{}{\frac{1}{2}}$} & & Woven & $3 \%$ & $3 \%$ & $4 \%$ & $6 \%$ & $1 \%$ & $20 \%$ & $85 \%$ & $68 \%$ \\
\hline & Staple & Knit & $9 \%$ & $7 \%$ & $4 \%$ & $6 \%$ & $1 \%$ & $20 \%$ & $77 \%$ & $61 \%$ \\
\hline & & Woven & $9 \%$ & $3 \%$ & $4 \%$ & $6 \%$ & $1 \%$ & $20 \%$ & $80 \%$ & $64 \%$ \\
\hline \multirow{2}{*}{ 岂 } & \multirow{2}{*}{$\begin{array}{l}\text { Ring } \\
\text { spun }\end{array}$} & Knit & $5 \%$ & $7 \%$ & $1 \%$ & $8 \%$ & $1 \%$ & $20 \%$ & $80 \%$ & $64 \%$ \\
\hline & & Woven & $5 \%$ & $3 \%$ & $2 \%$ & $8 \%$ & $1 \%$ & $20 \%$ & $83 \%$ & $66 \%$ \\
\hline \multirow{4}{*}{ 돌 } & \multirow{2}{*}{$\begin{array}{l}\text { Ring } \\
\text { spun }\end{array}$} & Knit & $18 \%$ & $2 \%$ & $1 \%$ & $8 \%$ & $1 \%$ & $20 \%$ & $73 \%$ & $58 \%$ \\
\hline & & Woven & $18 \%$ & $3 \%$ & $2 \%$ & $8 \%$ & $1 \%$ & $20 \%$ & $71 \%$ & $57 \%$ \\
\hline & \multirow{2}{*}{$\begin{array}{l}\text { Open } \\
\text { end }\end{array}$} & Knit & $10 \%$ & $2 \%$ & $1 \%$ & $8 \%$ & $1 \%$ & $20 \%$ & $80 \%$ & $64 \%$ \\
\hline & & Woven & $10 \%$ & $3 \%$ & $2 \%$ & $8 \%$ & $1 \%$ & $20 \%$ & $78 \%$ & $63 \%$ \\
\hline \multirow{2}{*}{ 응 } & & Knit & $8 \%$ & $7 \%$ & $4 \%$ & $6 \%$ & $1 \%$ & $20 \%$ & $78 \%$ & $62 \%$ \\
\hline & & Woven & $8 \%$ & $3 \%$ & $4 \%$ & $6 \%$ & $1 \%$ & $20 \%$ & $81 \%$ & $65 \%$ \\
\hline \multirow{2}{*}{ 差 } & & Knit & $3 \%$ & $7 \%$ & $0 \%$ & $6 \%$ & $1 \%$ & $20 \%$ & $85 \%$ & $68 \%$ \\
\hline & & Woven & $3 \%$ & $0 \%$ & $0 \%$ & $0 \%$ & $1 \%$ & $20 \%$ & $97 \%$ & $77 \%$ \\
\hline \multirow{2}{*}{ 产 } & & Knit & $18 \%$ & $7 \%$ & $0 \%$ & $8 \%$ & $1 \%$ & $20 \%$ & $70 \%$ & $56 \%$ \\
\hline & & Woven & $18 \%$ & $3 \%$ & $0 \%$ & $8 \%$ & $1 \%$ & $20 \%$ & $73 \%$ & $58 \%$ \\
\hline
\end{tabular}

Source: Higg MSI, based on data from Textile Exchange. 


\section{APPENDIX E: SCALING MILL EFFICIENCY (CLEAN BY DESIGN)}

To address thermal energy and electricity usage, many organizations have turned to efficiency programs as a cost-effective, reliable approach to reduce GHG emissions in material production (tier 2). Focusing on simple, low-cost measures could yield a 10 percent reduction per unit of production, while maximizing efficiency can deliver reductions of up to 20 percent per unit.

Extrapolating the simple, low-cost measures across 2,000 facilities demonstrates the impact scaling efficiency could have on the entire apparel industry. For example, using the low-hanging fruit approach of Clean by Design, we can expect $\mathrm{CO}_{2}$ reduction of 3,755 tonnes per facility (assuming a diversified portfolio of facilities). For 2,000 facilities, this is $7.5 \mathrm{Mt} \mathrm{CO}_{2}$. With an average cost per facility of US $\$ 50,000$ to $\$ 150,000$, the 2,000 facilities would require an investment of $\$ 100$ million to $\$ 300$ million (Aii 2021b; NRDC 2015).
Historical results from Clean by Design show the payback on the initial investment is 12 months (Aii 2021b; NRDC 2015). The average facility can save $\$ 200,000$ to $\$ 440,000$ annually, and thus the expected annual savings for 2,000 facilities is roughly $\$ 400$ million to $\$ 880$ million. ${ }^{24}$ 


\section{APPENDIX F: PROFILES OF RENEWABLE ENERGY IN KEY SOURCING COUNTRIES}

As outlined above, manufacturers can reduce GHG emissions through a variety of energy efficiency measures. However, there are limits to such measures, and manufacturers will need to use renewable electricity to reduce emissions (which is essential for brand customers that have set SBTs). Depending on the country of operations, a manufacturer's ability to access renewable electricity will vary. To illustrate the barriers and opportunities that manufacturers and brands face with renewable electricity, we partnered with the Clean Energy Investment Accelerator (CEIA) to summarize the state of play for renewables in key apparel and footwear source countries.

\section{Box F1 | Vietnam}

In recent years, Vietnam has become one of the most active markets for renewable energy development in Asia. As of 2020, 16 percent of the country's electricity was sourced from renewable energy (excluding hydroelectric). More than 8,000 megawatts (MW) of utility-scale solar farms are in operation and more than $8,000 \mathrm{MW}$ of rooftop solar projects have been completed over the last two years, with further growth expected. Vietnam is endowed with attractive wind power resources, particularly in coastal areas, and a revised feed-in-tariff for wind is expected to catalyze growth in the coming years.

Overall, $14,000 \mathrm{MW}$ of solar power and 6,000 MW of wind power are projected to be operating in Vietnam by 2025, which would account for approximately 30 percent of the country's power generation. However, Vietnam's overall power generation capacity is growing rapidly-expected to increase more than 150 percent by 2030-meaning that renewable energy's future position in Vietnam's overall electricity mix is uncertain.

As of 2021, corporate electricity users operating in Vietnam have two main options to procure renewable-based electricity:

- Rooftop Solar Photovoltaic (PV). "Solar-as-a-service" contracts in the form of PPAs and operating leases are widely available from solar project developers and investors. In most cases, rooftop solar
PPAs and leases offer immediate savings from utility electricity rates, and permitting for projects of 1 megawatt peak (MWp) or less is streamlined. Several multi-megawatt rooftop solar projects have already been completed, and a feed-in-tariff rate of 8.38 US cents per kilowatt hour and net billing mechanism are available to rooftop solar asset investors/owners.

- Off-Site Direct Power Purchase Agreement (DPPA) Pilot Program. 2021-22 is a pilot phase to implement the virtual PPA program, which allows off-site business-to-business PPA agreements-a first in Vietnam's electricity market. Solar and wind projects, at a minimum capacity of $30 \mathrm{MW}$, are eligible. Corporate energy users with clear and credible international sustainability and carbon reduction goals are eligible to participate in the pilot program. Supported by the Government of Vietnam, the pilot program is expected to enable 4001,000 MW of DPPA projects.

Apparel and footwear suppliers and brands are active participants in Vietnam's renewable energy growth. Several factories have contracted rooftop solar solutions (see Box F2 for a case study from Hansoll Textile) and have also played an active role in the DPPA pilot program. ${ }^{\mathrm{a}}$

Note: a. Corporate energy users interested in exploring renewable electricity options in Vietnam are encouraged to utilize the no-cost procurement tools and templates as well as the Vietnam Corporate Renewable Energy Procurement Guidebook authored by CEIA.

\section{Box F2 | Rooftop Solar in Vietnam: Hansoll Textile}

Hansoll Textile, a Korean-owned textile manufacturer with seven factories operating in Vietnam, is a member of the United Nations Framework Convention on Climate Change (UNFCCC) Fashion Industry Charter for Climate Action and has committed to reducing its GHG by 39 percent by 2030 (against a 2016 baseline). Hansoll sells to brands like Uniqlo, Gap, Target, and Walmart, and purchases from more than 70 suppliers in Vietnam. The company views rooftop solar for its factories in Vietnam as an important contributor to its climate goal.

Hansoll engaged in a 10-month collaboration with CEIA to assess the technical and economic feasibility of rooftop solar at its factories. Hansoll selected two factories in southern Vietnam to proceed with an aggregated Request for Proposals (RfPs) for no-CAPEX rooftop solar solutions. The competitive procurement resulted in Hansoll securing 15-year PPAs for a total of 7.8 MW.
The two projects cover approximately 20 percent of the two factories' annual electricity consumption and result in an estimated 10,882,519 kWh of annual solar electricity generation and $\$ 152,850$ (VND 3.75 billion) in cost savings in the first year of operation. Over 20 years, the projects are estimated to reduce Hansoll's GHG emissions by 77,065 tonnes $\mathrm{CO}_{2} \mathrm{e}$.

Hansoll will continue to implement renewable energy and energy efficiency initiatives, including considering rooftop solar at additional factories, as part of its company-wide GHG reduction strategy. 


\section{Box F3 | Indonesia}

Indonesia has established modest renewable energy goals. While little progress has been made toward achieving them, recent policy changes offer hope for growth. The 2014 National Energy Policy established a 23\% renewables target as a portion of the primary energy mix by 2025 and $31 \%$ by 2050 , but as of the start of 2020, only $12.3 \%$ of Indonesia's generation comes from renewables, and that figure has changed little since 2011. Deployment of renewable energy projects has been limited by insufficient incentives, lack of transparency and a complex regulatory regime.

Indonesia's power sector is dominated by the state-owned utility, PLN, which operates as a fully-integrated utility overseen by the Ministry of State-Owned Enterprises and the Ministry of Energy and Mineral Resources (MEMR). Policies, regulations and PLN guidelines prohibit independent power producers (IPPS) from selling electricity to any customers other than PLN.
Nevertheless, commercial and industrial buyers do have clean energy procurement options, and the policy landscape may be improving. The primary modes for on-site renewable energy generation are through 1) off-grid "self-consumption," 2). grid-connected parallel projects (including RTS) that are subject to PLN approval, 3). PLN's "RE Special Services" program that unfortunately under this program, the claim for utilizing RE doesn't meet international standards as the system for verifying or retiring certificates is not available, and 4). PLN's Renewable Energy Certificate (REC) whereby the certificate is issued by APX/TIGRs registry.

Power wheeling is available; however, in Indonesia's context, it is defined as common utilization of electricity transmission and distribution networks. And it only applies to companies with certain criteria defined by the regulation. A direct sale of electricity for private generators to end customers is prohibited. 
In 2016, the Chinese National Development and Reform Commission (NDRC) and National Energy Administration (NEA) set a 2030 strategy for the development of the energy sector in China. It outlines that between 2021 and 2030, incremental energy demand will be met by clean energy; in the power sector, 50 percent of total electricity will be generated from non-fossil fuels (renewables plus nuclear) by 2030; and that by 2050 non-fossil fuels will account for more than half of the total primary energy consumption.

Renewable energy in China has experienced rapid growth over the past two decades, dominated by wind and solar power. By the end of 2019, installed capacity of renewables reached $934 \mathrm{GW}$, taking up 42.5 percent of total power generation capacity; the share of renewables in electricity generation jumped to 29.1 percent of the total electricity generation, or 2,215.4 terawatt-hours (TWh). ${ }^{\mathrm{b}}$ Non-fossil fuels account for 15.9 percent of total primary energy. ${ }^{c}$

Since the adoption of the Renewable Energy Law in 2005, China has implemented tax reduction, subsidies, and other supporting policies for renewable energy projects. The 20 -year fixed feed-in tariff for wind and solar electricity based on the geographical resource region plays a pivotal role in accelerating renewable energy investment. China has been gradually cutting subsidies to renewable energy projects and promoting subsidy-free wind power and solar power pilots since 2019. ${ }^{\mathrm{d}}$ At the same time, NRDC and NEA issued the renewable energy obligation, which aims to promote renewable energy adoption and consumption by setting provincial renewable power and non-hydro renewable power consumption targets. ${ }^{e}$
The current power grid system cannot fully uptake renewable electricity due to its fluctuation and intermittence in production, especially in regions with abundant renewable energy resources but limited demand. To avoid curtailment, eleven provinces required new wind and solar projects to integrate energy storage systems, which increases investment costs for developers.

In addition, market mechanisms supporting the sustainable development of renewable energy need to be improved. For example, RECs for grid-parity projects have not been introduced. A peer-to-peer power trading market has not been established, which impedes the consumption of distributed renewable power, such as rooftop solar PV.

Currently there are three main options for corporate buyers to procure renewable energy in China: investing in distributed renewable energy projects like on-site solar, direct purchase from power companies, and Green Electricity Certificates (GECs). Distributed renewable energy projects have the most mature market, while direct purchase is only available in some provinces at the pilot stage. In 2021, the Zhejiang and Guangdong provinces released policies and regulations that enable integration of renewable electricity into the power supply., For example, the Guangdong Power Exchange Center issued a new pilot, Renewable Energy Trading Rules, enabling BASF and China Resources Power to enter into a deal through which the company purchases 100 percent renewable electricity established by China Resources Power for a plant in China. ${ }^{9}$ The first national pilot on green power trading launched in early September 2021. ${ }^{\mathrm{h}}$ The GEC/REC scheme in China allows companies to claim the environmental benefits associated with renewable energy generation, even if the electricity from a renewable power plant does not feed directly into the company's facilities.

Notes:

a. NDRC and NEA 2016

b. NEA 2021.

c. NDRC 2019.

d. Green Power Certificate Subscription Trading Platform. n.d. "China Green Power Certificate Subscription Trading Platform." Accessed October 15, 2021.

e. Fxbus 2021

f. Zhejiang Provincial Development and Reform Commission. 2021. "'Notice on the Pilot Work of Zhejiang Province's Green Power Market-Based Trading in 2021 ' Is Issued," June 21.

https://mwind.in-en.com/html/wind-2403502.shtml.

g. Process Worldwide 2021.

h. Liqiang 2021. 


\section{Box F5 | Bangladesh}

Bangladesh is endowed with abundant renewable energy resources including solar, wind, hydro, and geothermal. Yet, despite targets and policies to encourage renewable energy investments and development, the total installed share remains low. As of April 2021, the total installed capacity of renewable energy was only $724 \mathrm{MW}$-or approximately 3 percent of the total energy mix - of which, 64 percent is solar, 36 percent is hydro, and $<1$ percent is wind, biogas, and biomass. Approximately 50 percent of the renewable capacity is connected to the grid, of which 40 percent is solar and 60 percent is hydro, while off-grid renewable capacity is predominantly supplied through a growing five million Solar Home Systems. ${ }^{a}$

Bangladesh set a target in 2015 to install 3,100 MW renewable energy by 2021, including 1,740 MW from solar and 1,370 MW from wind. Developing solar energy has been the country's focus, as it is the most abundant and promising renewable energy resource. Towards that end, the government initiated the 500 MW Solar Power Mission, using 340 MW for commercial purposes. ${ }^{b}$ The government of Bangladesh has also recently introduced a net energy metering policy where individual energy producers can supply surplus electricity to the grid in return for decreased electricity bills. Approximately $20 \mathrm{MW}$ of net metering systems have already been installed. ${ }^{\circ}$

Bangladesh has land with a gross wind potential of over 30,000 MW. The government is assessing nine offshore wind areas under the Wind Resource Mapping Project, and wind turbines will be installed based on availability of wind velocity. The government has already taken steps to build wind power plants of $30 \mathrm{MW}$ and $60 \mathrm{MW}$ at the Mohuri Region of Feni and Magnamaght of
Chittagong. More recently, the State Minister for Power, Energy, and Mineral Resources stated that roughly 17 percent of Bangladesh's electricity will come from renewable energy sources by $2041{ }^{\mathrm{d}}$

Corporate electricity users in Bangladesh have several options for procuring renewables:

- Rooftop solar PV can be installed on commercial buildings to meet electricity demand. In March 2020, Robintex signed a 20 year PPA with Dhaka-based renewables developer, Joules Power Limited, for a 3.1 MW solar plant-Bangladesh's largest industrial solar rooftop project to be commissioned-which will also be connected to the grid and eligible for net metering. The Infrastructure Development Company Limited (IDCOL) is the largest recipient and disburser of financing for renewables, including rooftop solar projects.

- As an authorized issuance country by the board of the International REC Standard Foundation (I-REC Standard), individuals or organizations can act as a participant and hold or trade I-RECS. Participants wishing to purchase and redeem I-REC certifications must create an account of the I-REC registry. Participants can also be clients of an existing market-player who will hold accounts on their behalf. It is important to note that the Science Based Targets initiative only accepts I-RECs to count toward achievement of a company's target if the I-REC is retired in the same market it comes from. As this is not always the case, companies should confirm that I-RECs purchased follow this requirement when setting sciencebased targets.

Notes:

a. SREDA (Sustainable and Renewable Energy Development Authority). 2021. "National Database of Renewable Energy." http://www.renewableenergy.gov.bd/.

b. Hil Baky et al. 2017.

c. SREDA. 2021. "E-Service Desk for Solar." https://solar.sreda.gov.bd/nem/nemstatistics.php.

d. Dhaka Tribune. 2020. "Nasrul: 17\% electricity to come from renewable sources." Dhaka Tribune, August 25. https://www.dhakatribune.com/business/2020/08/25/nasrul-17-electricity-tocome-from-renewable-sources. 
Box F6 | India

Renewable energy is the fastest-growing source of energy in India, where total installed capacity increased 380 percent from 15 GW in 2010 to 73 GW in 2019. ${ }^{\text {a }}$

India has committed to add 175 GW renewable energy capacity by 2022, which will encompass $100 \mathrm{GW}$ of solar energy, $60 \mathrm{GW}$ of wind energy, as well as $9 \mathrm{GW}$ of small hydropower and $5 \mathrm{GW}$ from biomass-based projects. ${ }^{\text {a As }}$ of August 2021, total renewable energy capacity reached $100 \mathrm{GW}$, of which approximately $41 \mathrm{GW}$ is solar (ground mounted and rooftop), $39 \mathrm{GW}$ is wind, 4.8 GW is small-hydro, and 10.3 is GW biomass. ${ }^{b}$ While almost all of the hydro and biomass projects have met planned commitments, wind and solar power are rapidly expanding.

Wind and solar are the most commonly used technologies and the cheapest source of new power generation. ${ }^{c}$ However, financial and infrastructure barriers, as well as natural resource availability, present limitations for both technologies. Solar can be used economically across most parts of India with the exception of six states. Similarly, not every region would be able to rely on wind speeds fast enough to generate sufficient wind power. Northeastern states, for instance, have limited solar and wind generation, and most renewable energy is generated from small-hydro from the heavy rains and ample river systems.

The Indian renewable power market is constantly evolving. Corporate electricity users in India have several options for procuring renewable electricity:

- In its report Accelerating Corporate Procurement of Renewable Energy in India, World Business Council for Sustainable Development (WBCSD) provides an overview of the key terms of PPAs, the regulatory landscape, and market barriers, as well as financing options and recommendations for corporate buyers. ${ }^{c}$ An annual update on the current market and changing policies of corporate renewable PPAs is also published by WBCSD. In general, there are three common types of corporate renewable PPAs in India: for the sale of power from a solar rooftop project, for the sale of power from a utility scale renewable power project, and for the sale of power from a utility scale renewable power project structured as a captive project.

- Alternative corporate renewable PPA structures are expected to increase in popularity, including virtual PPAs (VPPAs), inter-state PPAs, and round-the-clock (RTC) PPAs. The price for renewable power via corporate renewable PPAs depends on applicable regulatory Open Access charges, which are revised every year and vary across states. Grasim Industries and Sangam Limited, both textile manufacturers, are some of the many companies procuring renewable power through corporation renewable PPAs in India. ${ }^{\mathrm{e}}$

- The Renewable Energy Certificate (REC) Registry of India manages all policies between renewable energy producers and corporate buyers. Currently, the only process allowed is online registration. Historically, RECs have been used as a market-based instrument to promote renewable energy and to facilitate compliance under renewable purchase obligations (RP0), One challenge has been a volatile REC market. Both in 2017 and 2020, the trading of RECs was suspended due to petitions against price changes by the Central Electricity Regulatory Commission (CERC). This pause increases the number of buyers in the pipeline, disrupting market equilibrium and potentially impacts the price of RECs. ${ }^{\dagger}$

Notes:

a. Elavarasan et al. 2020.

b. Invest India. 2021. "Snapshot: Creating a Sustainable World." National Investment Promotion \& Facilitation Agency. https://www.investindia.gov.in/sector/renewable-energy. c. WBCSD 2018.

d. C.L. Gupta Exports-a supplier to H\&M-did not leverage PPAs but did invest in a $2 \mathrm{MW}$ on-site rooftop solar PV project, which is expected to save the company roughly $\$ 100,000$ per year in energy costs and reduce annual emissions of 2,500 tons of $\mathrm{CO}_{2}$. IFC (International Finance Corporation). 2019. "Tailoring Energy Solutions That Fit India's Garment Suppliers." https://www.ifc.org/wps/wcm/connect/news_ext_content/ifc_external_corporate_site/news+and+events/news/impact-stories/tailoring-energy-solutions-fit-india-garment-suppliers. e. WBCSD 2021.

f. Bajaj, R. 2021. "How REC Trading Pause Will Impact India's Green Energy Aspiration." BusinessToday.In, January 25. https://www.businesstoday.in/opinion/columns/story/how-rec-tradingpause-will-impact-indias-green-energy-aspirations-285491-2021-01-25. 
1. As of September 2021, over 850 companies have approved sciencebased targets. Over 100 of these are in the apparel and footwear sector (brands, retailers, and manufacturers).

2. Based on annual GHG emissions of $49.4 \mathrm{Gt}$ (WRI 2020).

3. As described in Section 5, this reflects annual growth rates of 5 percent for synthetic and man-made cellulosic fibers and 1 percent for cotton and other natural fibers.

4. For the latest list of companies committed to the Science Based Targets initiative, see https://sciencebasedtargets.org/companies-taking-action/.

5. Due to limitations in data, footwear is not included in these calculations. However, the interventions discussed later in this report are generally applicable to both apparel and footwear.

6. Primary data refers to data measured directly from company operations. This could include, for instance, the electricity used to run a sewing machine for a specific product, contrasted with secondary or average data, which comes from non-company specific sources (such as the industry average of electricity needed to run a sewing machine).

7. The MSI and other LCA databases use European datasets for polyester because this is what is available. Ideally, the industry should have primary data across regions.

8. In reality, the percentage of fiber used in apparel differs by fiber type. This research assumes 66 percent for all fiber types to simplify the calculation.

9. This ratio may vary for individual companies or product types. Our intent was to use an average figure for the sector overall so that we could estimate total emissions. In calculating their GHG footprints, companies should use their own data and assumptions.

10. The MSI assumes 200 kilometers $(\mathrm{km})$ of transportation between each stage. Companies developing their GHG inventories should use actual transportation data where available.
11. Decitex is a measurement of linear density: the weight in grams of 10,000 meters of yarn.

12. According to the MSI, solution (or dope) dyeing has a 95 percent lower global warming score than batch dyeing.

13. The weighted average mix is derived from Bangladesh, China, the European Union, India, Indonesia, Korea, Pakistan, Turkey, the United States, and Vietnam.

14. Based on historical growth rates from "The Fiber Year 2020" (The Fiber Year Consulting 2020).

15. The FEM includes only Scope 1 and 2 emissions of manufacturers, not Scope 3 (for instance, chemical inputs).

16. Unless otherwise noted, reductions are for the period 2019-2030.

17. Ten percent is an assumption based on our experience and stakeholder input. This number can be adjusted in future analyses.

18. These figures are for tier 4 only.

19. Percentages shown are shares of total fiber amount-for instance, 30 percent of all polyester to be mechanically recycled.

20. For example, Livaeco ${ }^{\mathrm{Tm}}$ viscose staple fiber (BIRLA) and LENZING ${ }^{\mathrm{TM}}$ ECOVERO $^{\text {Tm }}$ viscose.

21. 536 million tonnes $\times 0.75 \times 0.50 \times 0.50$

22. 536 million tonnes $\times 0.75 \times 0.50 \times 0.50$

23. A number of stakeholders opined that the projections offered in the first draft (for instance, 50 percent recycled polyester, 10 percent organic cotton by 2030) were not realistic. We provide further explanation in Section 7.2 .

24. These figures are based on scaling simple, low-cost measures for efficiency which result in 10 percent reductions. Maximizing efficiency can deliver reductions up to 20 percent. 
REFERENCES

adidas. 2019. "Environmental Good Practice Guide \& Toolkit." https://www. adidas-group.com/media/filer_public/1b/28/1b28elcc-c702-4dd4-8f1d4779ca61f083/envgoodpracticetoolkit_en_2019.pdf.

adidas. 2021. "Global Factory Lists." https://www.adidas-group.com/ en/sustainability/managing-sustainability/human-rights/supply-chainstructure/.

Aii (Apparel Impact Institute), 2021a. "Program Areas." https://apparelimpact. org/program-areas/.

Aii. 2021b. "What Is Clean by Design." https://apparelimpact.org/case_study/ what-is-cbd/.

Allen, M., M. Babiker, Y. Chen, H. de Coninck, S. Connors, R. van Diemen, O.P. Dube, et al. 2018. "Summary for Policymakers." In Global Warming of $1.5^{\circ} \mathrm{C}$. An IPCC Special Report on the Impacts of Global Warming of $1.5^{\circ} \mathrm{C}$ above Pre-industrial Levels and Related Global Greenhouse Gas Emission Pathways, in the Context of Strengthening the Global Response to the Threat of Climate Change, Sustainable Development, and Efforts to Eradicate Poverty. Geneva: Intergovernmental Panel on Climate Change (IPCC). https://www.ipcc.ch/ site/assets/uploads/sites/2/2019/05/SR15_SPM_version_report_LR.pdf.

ASU (Arizona State University). 2017. "New ASU, Vietnam Alliance Will Amplify Long-Standing Partnership." ASU News, May 31. https://news. asu.edu/20170531-new-asu-vietnam-alliance-will-amplify-long-standingpartnership.

Berg, A., K.H. Magnus, S. Kappelmark, A. Granskog, L. Lee, C. Sawers, and P. Polgampola. 2020. "Fashion on Climate: How the Fashion Industry Can Urgently Act to Reduce Its Greenhouse Gase Emissions." McKinsey \& Company and Global Fashion Agenda. https://www.mckinsey.com/ /media/ mckinsey/industries/retail/our\%20insights/fashion\%20on\%20climate/ fashion-on-climate-full-report.pdf.

Bronson, K.F. 2008، "Nitrogen Use Efficiency of Cotton Varies with Irrigation System." Better Crops 92 (4): 20-22. http://www.ipni.net/publication/ bettercrops.nsf/0/6830993995A77AC28525798000708F74/\$FILE/Better\%20 Crops\%202008-4\%20p20.pdf.

C\&A. 2018. "Our Suppliers' Factory List." https://sustainability.c-and-a.com/ uk/en/sustainability-report/2018/suppliers-list/.

Candiani Denim. 2019. "Recycling at Candiani." YouTube. https://www. youtube.com/watch?v=rfuc-zOtgXc

Cotton Incorporated. 2017. "LCA Update of Cotton Fiber and Fabric Life Cycle Inventory." Cary, NC: Cotton Incorporated. https://cottontoday.cottoninc.com/ wp-content/uploads/2019/11/2016-LCA-Full-Report-Update.pdf.

Cotton Incorporated. 2021. "Monthly Economic Letter: Cotton Market Fundamentals \& Price Outlook." Cotton Incorporated, February. https://www. cottoninc.com/wp-content/uploads/2021/02/2021-02-Monthly-EconomicLetter.pdf.

Daystar, J. 2021. Personal communication between the authors and Jesse Daystar, Cotton Incorporated. April 26, 2021.
Drew, D., S. Gillick-Daniels, A. Dickerson, and E. Metzger. 2021. "Square Your Circle: How to Assess the Environmental Impact of Reuse Business Models in Apparel." Washington, DC: World Resources Institute (WRI), https://www.wri. org/research/square-your-circle-environmental-impact-reuse-model.

EIA (United States Energy Information Administration). 2020. "FAQs." https:// www.eia.gov/tools/faqs/faq.php.

Elavarasan, R.M., G.M. Shafiullah, S. Padmanaban, N.M. Kumar, A. Annam, A.M. Vetrichelvan, L. Mihet-Popa, and J.B. Holm-Nielsen. 2020. "A Comprehensive Review on Renewable Energy Development, Challenges, and Policies of Leading Indian States with an International Perspective." IEEE Access (8): 74432-57. doi:10.1109/ACCESS.2020.2988011.

EMF (Ellen MacArthur Foundation), 2015. "Towards a Circular Economy: Business Rationale for an Accelerated Transition." Cowes, United Kingdom: EMF, https://www.ellenmacarthurfoundation.org/assets/downloads/TCE_ Ellen-MacArthur-Foundation_9-Dec-2015.pdf.

EMF. 2021. "What Is a Circular Economy?" https://ellenmacarthurfoundation. org/topics/circular-economy-introduction/overview.

Farfetch. 2020. "Understanding the Environmental Savings of Buying Pre-owned Fashion." Farfetch, QSA, ICARO, and LWARB. https://cdn-static. farfetch-contents.com/content/UP/PRODUCTION/LANDING-PAGES/ SUSTAINABILITY-CALC/Understanding\%20the\%20Environmental\%20 Savings\%20of\%20Pre-owned_Farfetch\%20Report\%202020.pdf.

FENC (Far Eastern New Century). 2018. "FENC Launches Taiwan's First Green Bond Verified by a Third Party." FENC, January 8. http://www.fenc.com/news/ news_detail.aspx?lang=en\&id $=4130$.

Franzluebbers, A.J. 2010. "Achieving Soil Organic Carbon Sequestration with Conservation Agricultural Systems in the Southeastern United States." Soil Science Society of America Journal 74 (2): 347-57. doi:10.2136/sssaj2009.0079.

Funk, P, and R. Hardin. 2012. "Cotton Gin Electrical Energy Use Trends and 2009 Audit Results." Applied Engineering in Agriculture 28 (4): 503-10. doi:10.13031/2013.42078.

Fxbus. 2021. "Guangdong's First Renewable Energy Deal," June 22. https:// www.fxbus.com/kx/202106221330302073.html.

GA Circular. 2019. "Full Circle: Accelerating the Circular Economy for Post-consumer PET Bottles in Southeast Asia." Singapore: GA Circular. https://ubuntoo-assets.s3.amazonaws.com/uploads/blog_document/ document/107/Full_Circle_-_Final_Report.pdf.

GaBi. 2019. "Process Data Set: Polyethylene Terephthalate Bottle Grade Granulate (PET) via PTA; via Purified Terephthalic Acid (PTA) and Ethylene Glycol; Single Route, at Plant; $1.38 \mathrm{~g} / \mathrm{Cm} 3,192.17 \mathrm{~g} / \mathrm{Mol}$ per Repeating Unit (En)." http://gabi-documentation-2020.gabi-software.com/xml-data/ processes/4b2420b3-8f56-45f1-984d-173a9298ef4a.xml.

Global Solar Atlas. 2021. "Global Solar Atlas." https://globalsolaratlas.info/ map?c=11.609193,8.261719,3.

Global Wind Atlas. 2021. "Global Wind Atlas." https://globalwindatlas.info. Heliogen. 2021. "Unlocking the Power of Sunlight." https://heliogen.com/. 
Hil Baky, Md.A., Md.M. Rahman, and A.K.M.S. Islam. 2017. "Development of Renewable Energy Sector in Bangladesh: Current Status and Future Potentials." Renewable and Sustainable Energy Reviews 73 (June): 1184-97. doi:10.1016/j.rser.2017,02.047.

H\&M Group. 2021a. "Supply Chain." https://hmgroup.com/sustainability/ leading-the-change/transparency/supply-chain/.

H\&M Group. 2021b. "H\&M Group's Sustainability Work Attracts Bond Market Attention." H\&M Group, February 18. https://hmgroup.com/news/hm-groupssustainability-work-attracts-bond-market-attention/.

IISD (International Institute for Sustainable Development). 2021. "Responsible Business." https://www.iisd.org/topics/responsible-business.

Liqiang, H. 2021. "China Launches Pilot Direct Trading of Green Power." China Daily, September 8. https://s.chinadailyhk.com/V3QNji.

Loop Industries, Inc. 2020. "Loop Industries Announces Signature of Multiyear Supply Agreement with Beauty Leader L'Oréal." Loop Industries, Inc., March 6. https://www.loopindustries.com/cms/loop-industries-announcessignature-of-multi-year-supply-agreement-with-beauty-leader-loreal/.

Main, C.L., L.T. Barber, R.K. Boman, K. Chapman, D.M. Dodds, S. Duncan, K.L. Edmisten, et al. 2013. "Effects of Nitrogen and Planting Seed Size on Cotton Growth, Development, and Yield." Agronomy Journal 105 (6): 1853-59. doi:10.2134/agronj2013.0154.

McDonough, W. 2021. "Cradle to Cradle." William McDonough. https:// mcdonough.com/cradle-to-cradle/.

Morlet, A., R. Opsomer, S. Herrmann, L. Balmond, C. Gillet, L. Fuchs. 2017. "A New Textiles Economy: Redesigning Fashion's Future." EMF and Circular Fibres Initiative. https://ellenmacarthurfoundation.org/a-new-textileseconomy.

Mullins, G.L., and C.H. Burmester. 1990. "Dry Matter, Nitrogen, Phosphorus, and Potassium Accumulation by Four Cotton Varieties." Agronomy Journal 82 (4): 729-36. doi:10.2134/agronj1990.00021962008200040017x.

National Agricultural Statistics Service. 2019, "2018 Irrigation and Water Management Survey, Volume 3, Special Studies, Part 1." Washington, DC: USDA (United States Department of Agriculture), https://www.nass.usda. gov/Publications/AgCensus/2017/0nline_Resources/Farm_and_Ranch_ Irrigation_Survey/fris.pdf.

NDRC (National Development and Reform Commission). 2019. "Notice on Establishing and Improving the Guarantee Mechanism of Renewable Energy Power Consumption (Fagai Energy (2019) No. 807)," May 10. https://zfxxgk. ndrc.gov.cn/web/iteminfo.jsp?id=16176.

NDRC and NEA (National Energy Administration). 2016. "Notice on Printing and Distributing the Energy Production and Consumption Revolution Strategy (2016-2030)," December 29. https://www.ndrc.gov.cn/xxgk/zcfb/ tz/201704/t20170425_962953.html.

NEA. 2021. "Announcement of the National Energy Administration on the 2020 National Renewable Energy Power Development Monitoring and Evaluation Results," June 20. http://zfxxgk.nea.gov.cn/2021-06/20/c_1310039970.htm.
NRDC (Natural Resources Defense Council). 2015. "Clean by Design: NRDC's Green Supply Chain Initiative to Clean Up the Fashion Industry." New York: NRDC. https://www.nrdc.org/sites/default/files/cbd-initiative-fs.pdf.

Patagonia. 2021a. "Worn Wear: Used Patagonia Clothing \& Gear." https:// wornwear.patagonia.com/.

Patagonia. 2021b. "Recycled Cotton Fabric." https://www.patagonia.com/ our-footprint/recycled-cotton.html.

Process Worldwide. 2021. "BASF to Use 100\% Renewable Electricity at Zhanjiang Verbund Site," June 24. https://www.process-worldwide.com/ basf-to-use-100-renewable-electricity-at-zhanjiang-verbund-site-a-1033558/.

Putt del Pino, S., E. Metzger, D. Drew, and K. Moss. 2017. "Elephant in the Boardroom: Why Unchecked Consumption Is Not an Option in Tomorrow's Markets." Washington, DC: WRI. https://www.wri.org/research/elephantboardroom-why-unchecked-consumption-not-option-tomorrows-markets.

Quantis. 2018. "Measuring Fashion: Insights from the Environmental Impact of the Global Apparel and Footwear Industries." Quantis. https://quantis-intl. com/report/measuring-fashion-report/.

Quantis. 2021. "World Apparel \& Footwear Life Cycle Assessment Database." https://quantis-intl.com/metrics/databases/waldb-apparel-footwear/.

Ranganathan, J., R. Waite, T. Searchinger, and J. Zionts. 2020. "Regenerative Agriculture: Good for Soil Health, but Limited Potential to Mitigate Climate Change." WRI. https://www.wri.org/insights/regenerative-agriculture-goodsoil-health-limited-potential-mitigate-climate-change.

Renewal Workshop. 2021. "A Sustainable Cycle." https://renewalworkshop. $\mathrm{com} /$.

Rent the Runway. 2021. "Rent the Runway." https://www.renttherunway.com/ how_renting_works.

Roos, S., M. Larsson, and C. Jönsson. 2019. "Supply Chain Guidelines: Vision and Ecodesign Action List." Göteborg, Sweden: RISE AB and Mistra. http:// mistrafuturefashion.com/wp-content/uploads/2019/10/Supply-ChainGuidelines_S.Roos-Mistra-Future-Fashion-report.pdf.

SAC (Sustainable Apparel Coalition), 2020a. "A Decade in Review, 2010-2020." 0akland, CA: SAC. http://rz5632gw5fl131l6k1nospb4-wpengine.netdna-ssl. com/wp-content/uploads/2021/02/SAC-A-Decade-in-Review.pdf.

SAC. 2020b. "Learn More about the MSI Contributor." https://msicontributor. higg.org/page/learn-more-read-this-first.

SAC. 2020c. "Higg Materials Sustainability Index Methodology," July 31. https://howtohigg.org/wp-content/uploads/2020/07/Higg-MSIMethodology-July-31-2020.pdf.

SAC. 2020d "Higg Materials Sustainability Index," December 18, https:// apparelcoalition.org/higg-msi-data-update-2020/.

SAC. 2021a. "Higg MSI Change Log." https://howtohigg.org/higg-msi/higgmsi-change-log/.

SAC. 2021b. "FAQ." https://howtohigg.org/higg-msi/faq/. 
Sadowski, M., C. Yan, C. Cummis, and N. Aden. 2019. "Apparel and Footwear Sector Science-Based Targets Guidance." Washington, DC: SBTi (Science Based Targets initiative) and WRI. https://sciencebasedtargets.org/ resources/legacy/2019/06/SBT_App_Guide_final_0718.pdf.

Sandin, G., S. Roos, B. Spak, B. Zamani, and G. Peters. 2019. "Environmental Assessment of Swedish Clothing Consumption: Six Garments, Sustainable Futures." Göteborg, Sweden: RISE AB and Mistra. http://mistrafuturefashion. com/wp-content/uploads/2019/08/G.Sandin-Environmental-assessment-ofSwedish-clothing-consumption.MistraFutureFashionReport-2019.05.pdf.

Searchinger, T., and R. Heimlich. 2015. "Avoiding Bioenergy Competition for Food Crops and Land." Working Paper. Washington, DC: WRI. https://www. wri.org/research/avoiding-bioenergy-competition-food-crops-and-land.

Textile Exchange. 2014. "The Life Cycle Assessment of Organic Cotton Fiber-A Global Average." Textile Exchange.

Textile Exchange. 2019a. "Corporate Fiber \& Materials Benchmark." Textile Exchange. https://textileexchange.org/wp-content/uploads/2019/09/ CFMB_2019_Fiber-Conversion-Methodology.pdf.

Textile Exchange. 2019b. "Preferred Fiber \& Materials Market Report 2019." Textile Exchange. https://store.textileexchange.org/wp-content/uploads/ woocommerce_uploads/2019/11/Textile-Exchange_Preferred-Fiber-MaterialMarket-Report_2019-1.pdf.

Textile Exchange. 2020a. "Preferred Fiber \& Materials Market Report 2020." Textile Exchange. https://textileexchange.org/wp-content/uploads/2020/06/ Textile-Exchange_Preferred-Fiber-Material-Market-Report_2020.pdf.

Textile Exchange. 2020b. "What Is the Definition of a 'Preferred' Fiber or Material?" https://textileexchange.org/faqs/what-is-the-definition-of-apreferred-fiber-or-material/.

Textile Exchange. 2021. "Preferred Fiber and Material Matrix." https:// textileexchange.org/pfm-matrix/.
The Economist. 2020. "Vietnam Grapples with an Unexpected Surge in Solar Power." The Economist, January 25. https://www.economist.com/ asia/2020/01/25/vietnam-grapples-with-an-unexpected-surge-in-solarpower.

The Fiber Year Consulting. 2020. "The Fiber Year 2020: World Survey on Textiles \& Nonwovens." The Fiber Year Consulting (20).

Tudball, M., and S. Mair. 2018. "A Review of RPET Market." Presented at the Textile Exchange Sustainability Conference, Milan, October 22-24.

VF Corporation. 2020. "VF Corporation Closes Inaugural €500 Million Green Bond to Support Key Sustainability Initiatives," February 27. https://www.vfc. com/investors/news-events-presentations/press-releases/detail/1712/vfcorporation-closes-inaugural-500-million-green-bond.

Waslander, J., J. Bos, and Y. Wu. 2021. "Banking Beyond Climate Commitments: Transforming Client Engagement and Products \& Services for a Net-Zero Emissions Future." Working Paper. Washington, DC: WRI. https://www.wri. org/research/banking-beyond-climate-commitments.

WBCSD (World Business Council for Sustainable Development). 2018. "Accelerating Corporate Procurement of Renewable Energy in India." https:// www.wbcsd.org/contentwbc/download/5097/68189/1.

WBCSD. 2021. "Corporate Renewable PPAs in India: Market \& Policy Update." https://www.wbcsd.org/contentwbc/download/11241/165820/1.

WM0 (World Meteorological Organization). 2021. "Climate Change and Impacts Accelerate," September 15. https://public.wmo.int/en/media/pressrelease/climate-change-and-impacts-accelerate.

WRI. 2020. "World Greenhouse Gas Emissions: 2016," February 3. https:// www.wri.org/data/world-greenhouse-gas-emissions-2016.

Yale School of the Environment. 2021. "Center for Industrial Ecology." https:// cie.research.yale.edu/about-center. 


\section{ACKNOWLEDGMENTS}

Thank you to the contributors, reviewers, editors, and designers who shared their time, insights, and creativity.

We are particularly grateful to Paula Bernstein of Higg and Joël Mertens of the Sustainable Apparel Coalition for helping to develop the GHG calculations for this report.

Contributors: Kylee Chang (WRI), Cynthia Cummis (WRI), Min Yuan (WRI), Paula Bernstein (Higg), Joël Mertens (Sustainable Apparel Coalition)

WRI Reviewers: Kevin Moss, Deborah Drew, Mofan Zhang, Robi Robichaud, Deepak Sriram Krishnan

External Reviewers: Linda Greer (Institute for Public and Environmental Affairs), Matt Thurston (REI), Brian Au (QUANTEXT Consulting Limited), Matthew Guenther (TAL Apparel Limited), Beth Jensen and La Rhea Pepper (Textile Exchange), Steven Pires and Jesse Daystar (Cotton Incorporated), Evan Scandling (Allotrope Partners), Liam Salter (RESET Carbon Ltd), Artemisa Aguirre (National Commission for Better Regulation)

We are also grateful for the dozens of individuals who provided input to and feedback on the first draft of the Roadmap, which was published for external review in September 2020.

This report was made possible through the generous funding of the Laudes Foundation.

\section{ABOUTTHE AUTHORS}

Michael Sadowski is a a research consultant with WRI, where he works on climate change and the apparel sector. He has over 20 years of experience working across sectors on sustainable development issues.

Contact: michael.sadowski.5@wri.org

Lewis Perkins is the President of the Apparel Impact Institute and leads the organization's mission to identify, fund, and scale programs to drive positive impact in the fashion sector. He is the former President of the Cradle to Cradle Products Innovation Institute.

Contact: lewis@apparelimpact.org

Emily McGarvey is a consultant for the Apparel Impact Institute where she works on strategy, stakeholder engagement, and special projects.

Contact: emily@apparelimpact.org 


\section{ABOUTWR}

World Resources Institute is a global research organization that turns big ideas into action at the nexus of environment, economic opportunity, and human well-being.

\section{Our Challenge}

Natural resources are at the foundation of economic opportunity and human well-being. But today, we are depleting Earth's resources at rates that are not sustainable, endangering economies and people's lives. People depend on clean water, fertile land, healthy forests, and a stable climate. Livable cities and clean energy are essential for a sustainable planet. We must address these urgent, global challenges this decade.

\section{Our Vision}

We envision an equitable and prosperous planet driven by the wise management of natural resources. We aspire to create a world where the actions of government, business, and communities combine to eliminate poverty and sustain the natural environment for all people.

\section{Our Approach}

COUNT IT

We start with data. We conduct independent research and draw on the latest technology to develop new insights and recommendations. Our rigorous analysis identifies risks, unveils opportunities, and informs smart strategies. We focus our efforts on influential and emerging economies where the future of sustainability will be determined.

CHANGE IT

We use our research to influence government policies, business strategies, and civil society action. We test projects with communities, companies, and government agencies to build a strong evidence base. Then, we work with partners to deliver change on the ground that alleviates poverty and strengthens society. We hold ourselves accountable to ensure our outcomes will be bold and enduring.

SCALE IT

We don't think small. Once tested, we work with partners to adopt and expand our efforts regionally and globally. We engage with decision-makers to carry out our ideas and elevate our impact. We measure success through government and business actions that improve people's lives and sustain a healthy environment.

\section{ABOUT APPAREL IMPACT INSTITUTE}

Aii identifies, funds, scales, and measures proven quality solutions to accelerate positive impact in the fashion industry. Aii looks for scalable solutions and best practices that can be applied to the entire value chain. By improving upon the environmental footprint of the current industrial model the key to unlocking the future will involve innovations of materials, manufacturing, and business models. 
Cccreative (P) Copyright 2021 World Resources Institute. This work is licensed under the Creative Commons Attribution 4.0 International License. ccommons (-) To view a copy of the license, visit http://creativecommons.org/licenses/by/4.0/ 